\title{
Performance Assessment in Support of the 1996 Compliance Certification Application for the Waste Isolation Pilot Plant
}

\author{
J. C. Helton, ${ }^{1}$ D. R. Anderson, ${ }^{2}$ H.-N. Jow, ${ }^{2}$ M.G. Marietta, ${ }^{2}$ G. Basabilvazo ${ }^{3}$ \\ 1 Department of Mathematics, Arizona State University, Tempe, AZ 85287-1804 USA \\ 2 Sandia National Laboratories, Albuquerque, NM 87185-1328 USA \\ - 3 U.S. Department of Energy, Carlsbad, NM 88221 USA
}

\begin{abstract}
The conceptual and computational structure of a performance assessment (PA) for the Waste Isolation Pilot Plant (WIPP) is described. Important parts of this structure are (i) maintenance of a separation between stochastic (i.e., aleatory) and subjective (i.e., epistemic) uncertainty, with stochastic uncertainty arising from the many possible disruptions that could occur over the 10,000 yr regulatory period that applies to the WIPP and subjective uncertainty. arising from the imprecision with which many of the quantities required in the analysis are known, (ii) use of Latin hypercube sampling to incorporate the effects of subjective uncertainty, (iii) use of Monte Carlo (i.e., random) sampling to incorporate the effects of stochastic uncertainty, and (iv) efficient use of the necessarily limited number of mechanistic calculations that can be performed to support the analysis. The WIPP is under development by the U.S. Department of Energy (DOE) for the geologic (i.e., deep underground) disposal of transuranic (TRU) waste, with the indicated PA supporing a ${ }_{6}$ Compliance Certification Application (CCA) by the DOE to the U.S. Environmental Protection Agency (EPA) in October 1996, for the necessary certifications for the WIPP to begin operation. If certified, the WIPP will be the first operational facility in the United States for the geologic disposal of radioactive waste.
\end{abstract}

Key Words: Aleatory uncertainty, compliance certification application, epistemic uncertainty, Latin hypercube sampling, performance assessment, radioactive waste, stochastic uncertainty, subjective uncertainty, transuranic waste, Waste Isolation Pilot Plant, 40 CFR 191, 40 CFR 194. 


\section{Introduction}

The Waste Isolation Pilot Plant (WIPP) is under development by the U.S. Department of Energy (DOE) for the geologic disposal of transuranic (TRU) waste that has been generated at government defense installations in the United States. ${ }^{1.2}$ The WIPP is located in southeastern New Mexico in an area of low population density . approximately $42 \mathrm{~km}(26 \mathrm{mi}$ ) east of Carlsbad. Waste disposal will take place in excavated chambers (i.e., waste disposal panels) in a bedded salt formation, the Salado Formation (Fm), approximately $655 \mathrm{~m}(2150 \mathrm{ft})$ below the land surface (Fig. 1). The Salado Fm is contained in the Delaware Basin, which is a large sedimentary basin located in southeastern New Mexico and western Texas (Sect. 1.5.3, Vol. 3, Ref. 3; Chapt. 2, Ref. 5).

The sequence of events that led to the development of the WIPP by the DOE for the disposal of TRU waste in bedded salt began in 1955 when the Atomic Energy Commission (AEC), part of which later became the DOE, asked the National Academy of Science (NAS) to examine disposal options for radioactive waste (Sect. 1.5.1, Ref. 6; see Tables 1.5-1 and 1.5-2 of Ref. 6 for more details on the historical development of the WIPP than can be presented here). In response, the NAS reported in 1957 that, while various options and disposal sites were feasible, disposal in bedded salt was the most promising disposal method. ${ }^{7}$ From that point through the early 1970s, Oak Ridge National Laboratory conducted radioactive-waste disposal experiments, most notably Project Salt Vault in an abandoned salt mine near Lyons, Kansas. ${ }^{8}$ Although the AEC considered using the mine as a repository, the discovery of boreholes in the nearby area prompted the AEC to search for more suitable sites. 9

At the invitation of New Mexico's governor, the AEC investigated the Delaware Basin in the Carlsbad area of New Mexico. After an initial examination, a potential site was identified in the 1970s. The site was named the Waste Isolation Pilot Plant (WIPP) in January 1976.10 The regional site-characterization phase of this potential waste disposal sitell ended with the preparation of an Environmental Impact Statement (EIS) in $1980,{ }^{1}$ as required by the National Environmental Policy Act of 1969 (NEPA). ${ }^{12}$ In response to the EIS, the DOE decided to proceed with a preliminary design phase at this site.

During the 1970s, the mission of the WIPP, and thus the design, ${ }^{13}$ varied between including and not including defense high-level waste (HLW) in addition to TRU waste. However, with passage of the National Security and Military Applications of Nuclear Energy Authorization Act of $1980,{ }^{14}$ Congress defined the WIPP as a research and development facility for the storage and disposal of TRU waste, and exempted the WIPP from regulation by the U.S. Nuclear Regulatory Commission.

In 1981, the "Stipulated Agreement" and "Consultation and Cooperation Agreement" defined the WIPP's relationship with the State of New Mexico and stipulated specific geotechnical experiments required by the state. ${ }^{15}$ 


\section{DISCLAIMER}

This report was prepared as an account of work sponsored by an agency of the United States Government. Neither the United States Government nor any agency thereof, nor any of their employees, make any warranty, express or implied, or assumes any legal liability or responsibility for the accuracy, completeness, or usefulness of any information, apparatus, product, or process disclosed, or represents that its use would not infringe privately owned rights. Reference herein to any specific commercial product, process, or service by trade name, trademark, manufacturer, or otherwise does not necessarily constitute or imply its endorsement, recommendation, or favoring by the United States Government or any agency thereof. The views and opinions of authors expressed herein do not necessarily state or reflect those of the United States Government or any agency thereof. 


\section{DISCLAIMER}

Portions of this document may be illegible in electronic image products. Images are produced from the best available original document. 
After much planning, construction of the WIPP began in 1983.16.17 Experiments to characterize the local disposal system followed. ${ }^{18-20}$ In preparation for the WIPP's opening, a Supplemental EIS was published in 1990.2

In the Waste Isolation Pilot Plant Land Withdrawal Act of 1992 (LWA),21 Congress defined the process by' which WIPP's compliance with applicable regulations would have to be evaluated and transferred ownership of the WIPP site to the DOE. This act officially marked the transition from the construction and disposal-systemcharacterization phase to the compliance and testing phases, although these phases had begun unofficially in 1985 when the EPA issued 40 CFR $191^{22}$ and in 1989 when Sandia National Laboratories (SNL) first began to assess performance of the WIPP using the EPA standard. ${ }^{23-25}$ Additional performance assessments (PAs) were carried out for the WIPP in 1990, 1991 and 1992,3.4,26 with summaries of the 1991 and 1992 PAs available in the journal literature. ${ }^{27-30}$

The efforts to produce a PA for the WIPP to satisfy the requirements in 40 CFR 191 began in 1992, when Congress passed the LWA in which it established several mandates. First, Congress required that the DOE demonstrate compliance to the final disposal standards codified in 40 CFR Part 191, Subparts B and C, prior to opening the WIPP for the disposal of TRU waste.22,31 Second, Congress mandated that the DOE submit an application to the EPA seeking certification of the DOE's compliance demonstration. Third, Congress mandated that the EPA issue certification criteria to judge the adequacy of the DOE's application. The EPA met this obligation in February 1996 with the issuance of 40 CFR Part 194.32,33

This presentation describes a PA carried out at SNL to support the Compliance Certification Application (CCA) made by the DOE to the EPA in October 1996 for the certification of the WIPP for the disposal of TRU waste as mandated in the LWA.5 This PA will be referred to as the 1996 WIPP PA, with some documents also referring to it as the 1996 CCA PA or the 1996 WIPPCCA PA. This presentation is based in part on a preliminary description of the 1996 WIPP PA that was written in the summer of 1996 while the analysis was still in progress. ${ }^{34}$ When appropriate, changes to this preliminary description are made to better indicate what was done in the final analysis and also to provide more detail on what was done. In addition, the presentation of results from the analysis is now possible, which could not be done in the summer of 1996 as such results were not yet available. The intent is to give a high-level overview of the conceptual and computational structure of the 1996 WIPP PA with approximately equal coverage given to the individual parts of this large analysis. Further, references to additional and more detailed sources of information are given.

\section{Regulatory Requirements}

The conceptual structure of the 1996 WIPP PA ultimately derives from the regulatory requirements imposed on this facility. ${ }^{35,36}$ The primary regulation determining this structure is the U.S. EPA's standard for the geologic disposal of radioactive waste ( 40 CFR 191), ${ }^{22.31}$ which is divided into three parts. Subpart A applies to a disposal 
facility prior to decommissioning and limits annual radiation doses to members of the public from uaste managenent and storage operations. Subpart B applies after decommissioning and sets probabilistic limits on cumulative relcase: of radionuclides to the accessible environment for 10.000 yr (40 CFR 191.13) and assurance requirements to provide confidence that 40 CFR 191.13 will be met ( 40 CFR 191.14). Subpart B also sets limits on radiation doses to members of the public in the accessible environment for 10,000 yrs of undisturbed performance ( 40 CFR 191.15). Subpar C limits radioactive contamination of certain sources of groundwater for $10,000 \mathrm{yr}$ after disposal ( $40 \mathrm{CFR}$ 191.24). The DOE must provide a reasonable expectation that the WIPP will comply with the requirements of Subparts B and C of 40 CFR 191.

The following is the central requirement in 40 CFR 191. Subpart B, and the primary determinant of the conceptual structure of the 1996 WIPP PA (p. 38086, Ref. 22):

\section{§ 191:13 Containment requirements:}

(a) Disposal systems for spent nuclear fuel or high-level or transuranic radioactive wastes shall be designed to provide a reasonable expectation, based upon performance assessments, that cumulative releases of radionuclides to the accessible environment for 10,000 years after disposal from all significant processes and events that may affect the disposal system shall: (1) Have a likelihood of less than one chance in 10 of exceeding the quantities calculated according to Table 1 (Appendix A); and (2) Have a likelihood of less than one chance in 1,000 of exceeding ten times the quantities calculated according to Table 1 (Appendix A).

(b) Performance assessments need not provide complete assurance that the requirements of 191.13(a) will be met. Because of the long time period involved and the nature of the events and processes of interest, there will inevitably be substantial uncertainties in projecting disposal system performance. Proof of the future performance of a disposal system is not to be had in the ordinary sense of the word in situations that deal with much shorer time frames. Instead, what is required is a reasonable expectation, on the basis of the record before the implementing agency, that compliance with 191.13(a) will be achieved.

Containment Requirement 191.13(a) refers to "quantities calculated according to Table 1 (App. A)," which means a normalized radionuclide release to the accessible environment based on the type of waste being disposed of. the initial waste inventory, and the release that takes place (App. A, Ref. 22). Table 1 (App. A) specifies allowable releases (i.e., release limits) for individual radionuclides and is reproduced as Table I of this presentation. The WIPP is intended for IRU waste, which is defined to be "waste containing more than 100 nanocuries of alphaemitting transuranic isotopes, with half-lives greater than twenty years, per gram of waste" (p. 38084, Ref. 22). The normalized release $R$ for transuranic waste is defined by

$$
R=\sum_{i}\left(Q_{i} / L_{i}\right)\left(1 \times 10^{6} \mathrm{Ci} / \mathrm{C}\right)
$$

where $Q_{i}$ is the cumulative release of radionuclide $i$ to the accessible environment during the 10,000 -yr period following closure of the repository $(\mathrm{Ci}), L_{i}$ is the release limit for radionuclide $i$ given in Table $I(\mathrm{Ci})$ and $C$ is the 
amount of transuranic wastc emplaced in the repository (Ci). In the 1996 WIPP PA. $C=3.44 \times 10^{6} \mathrm{Ci}_{3} .37$ Further. accessible environment means (i) the atmosphere, (ii) land surfaces. (iii) surface waters. (iv) oceans. and (v) all of the lithosphere that is beyond the controlled area; and controlled area means (i) a surface location. to be identified by: passive institutional controls, that encompasses no more than 100 square kilometers and extends horizontally no more than five kilometers in any direction from the outer boundary of the original location of the radioactive wastes in a disposal system and (ii) the subsurface underlying such a surface location.

As required by the LWA, the EPA also promulgated 40 CFR 194,32 where the following elaboration on the intent of 40 CFR 191.13 is given (pp. 5242-5243, Ref. 32):

\section{$\S 194.34$ Results of performance assessments.}

(a) The results of performance assessments shall be assembled into "complementary, cumulative distribution functions" (CCDFs) that represent the probability of exceeding various levels of cumulative release caused by all signficant processes and events. (b) Probability distributions for uncertain disposal system parameter values used in performance assessments shall be developed and documented in any compliance application. (c) Computational techniques, which draw random samples from across the entire range of the probability distributions developed pursuant to paragraph (b) of this section, shall be used in generating CCDFs and shall be documented in any compliance application. (d) The number of CCDFs generated shall be large enough such that, at cumulative releases of 1 and 10, the maximum CCDF generated exceeds the 99 th percentile of the population of CCDFs with at least a 0.95 probability. (e) Any compliance application shall display the full range of CCDFs generated. (f) Any compliance application shall provide information which demonstrates that there is at least a 95 percent level of statistical confidence that the mean of the population of CCDFs meets the containment requirements of $\S 191.13$ of this chapter.

In addition to the requirements in 40 CFR 191.13 and 40 CFR 194.34 just quoted, 40 CFR 191 and 40 CFR 194 contain many additional requirements for the certification of the WIPP for the disposal of TRU waste. However. it is the indicated requirements that determine the overall structure of the 1996 WIPP PA and are the primary focus of this presentation. A complete description of the requirements that are placed on the WIPP and how these requirements are addressed is available in the CCA (pp. XWALK-1 to XWALK-36, Ref. 5).

The results required in 191.13 and 194.34 determine the conceptual and computational structure of the 1996 WIPP PA and lead to an analysis based on three distinct entities (EN1, EN2, EN3): EN1, a probabilistic characterization of the likelihood of different futures occurring at the WIPP site over the next $10.000 \mathrm{yr}$, EN2, a procedure for estimating the radionuclide releases to the accessible environment associated with each of the possible futures that could occur at the WIPP site over the next 10,000 $\mathrm{yr}$; and EN3, a probabilistic characterization of the uncerainty in the parameters used in the definitions of EN1 and EN2. Together, EN1 and EN2 give rise to the CCDF specified in 191.13(a) (Fig. 2), and EN3 corresponds to the distributions indicated in 194.34(b).

The preceding entities arise from an attempt to answer three questions (Q1, Q2, Q3) about the WIPP: Q1, "What occurrences could take place at the WIPP site over the next 10,000 yr?"; Q2, "How likely are the different 
occurrences that could take place at the WIPP site over the next $10.000 \mathrm{yr}$ ?": Q3. "What are the consequences of the different occurrences that could take place at the WIPP site over the next $10.000 \mathrm{yr}$ ?": and one question (Q4) about the WIPP PA: Q4. "How much confidence should be placed in answers to the first threc questions?". In the WIPP PA. EN1 provides answers to Q1 and Q2: EN2 provides an answer to Q3: and EN3 provides an answer to Q4.

\section{Screening of Features, Events and Processes}

As just indicated, the 1996 WIPP PA is based on three distinct entities. Careful delinitions of how these entities are specified for the 1996 WIPP PA are given in Sects. 4 - 6. and are necessary for the computational implementation of the analysis. However, the start of a PA for a complex system goes through a preliminary, and often rather ill-defined, phase in which it must be decided what is to be. and hence what is not to be. included in the analysis. It is from this work that the formal definitions of these entities ultimately emerge.

In a very real sense, this work has been going on for the WIPP since its development was initiated in the 1970 s. and indeed, goes back to the beginning of the consideration of geologic disposal for radioactive wastes in the 1950s. This development work and the early PAs carried out for the WIPP certainly led to general ideas about what would be important with respect to the performance of a waste repository in bedded salt. However, a PA that is to be used in a regulatory context requires a formal development and documentation of what is to be included in. and excluded from. the analysis. For the 1996 WIPP PA, this initial and fundamental work was carried out in an activity referred to as the identification and screening of features. events and processes (FEPs) (Sect. 6.2. Ref. 5).

The regulatory requirements for an analysis of FEPs potentially important with respect to the WIPP derives from the following statement in 40 CFR 194 (p. 5242, Ref. 32):

\section{$\S 194.32$ Scope of performance assÉssments.}

... (e) Any compliance application(s) shall include information which: (l) identifies all potential processes, events or sequences and combinations of processes and events that may occur during the regulatory time frame and may affect the disposal system; (2) Identifies the processes, events or sequences and combinations of processes and events included in performance assessments; and (3) Documents why any processes, events or sequences and combinations of processes and events identified pursuant to paragraph (e)(1) of this section were not included in performance assessment results provided in any compliance application.

To meet the preceding requirements, a formal FEPs screening was carried out as part of the 1996 WIPP PA.

As a starting point, a list of potentially relevant FEPs was assembled from a compilation developed for the Swedish Nuclear Power Inspectorate (SKI). ${ }^{39}$ The SKI list is based on several FEP lists developed for other waste disposal programs and constituted the best documented and most comprehensive starting point for the WIPP PA. WIPP-specific FEPs were added to the SKI list, and the combined list was edited to remove redundancy and 
ambiguity, resulting in a FEPs list (Attachment 1, App. SCR, Ref. 5) that was appropriate for the WIPP (Sect. 6.2.1. Ref. 5).

This list was then carefully analyzed to identify the FEPs that should be incorporated into the computational structure of the 1996 WIPP PA and also the FEPs that did not require incorporation into this structure. Decisions to remove (i.e., screen out) FEPs from the computational structure used for the 1996 WIPP PA were based on the following criteria: regulatory exclusion (SO-R), low probability (SO-P), and low consequence (SO-C). The three screening criteria derive from specific regulatory requirements (Sect. 6.2.2.1, Ref. 5). In particular, the screening criterion SO-R arises because certain types of FEPs are specifically excluded from consideration in PAs to assess the compliance of the WIPP with $40 \mathrm{CFR} 191$ (e.g., the statement "Inadvertent and intermittent intrusion by drilling for resources (other than those resources provided by the waste in the disposal system or engineered baniers designed to isolate such waste) is the most severe human intrusion scenario" in 40 CFR 194.33 (p. 5242, Ref. 32) excludes many potential human disruptions of the WIPP from consideration); the screening criterion SO-P arises because low probability FEPs are specifically excluded from consideration in PAs to assess the compliance of the WIPP with 40 CFR 191 (i.e., the statement "Performance assessments need not consider processes and events that have less than one chance in 10,000 of occurring over 10,000 years" appears in 40 CFR 194.34 (p. 5242, Ref. 32)); and the screening criterion SO-C arises because the occurrence of many FEPs has no effect on the location of the CCDF used to assess compliance with $40 \mathrm{CFR} 191.13$ (i.e., the statement "The results of performance assessments shall be assembled into "complementary cumulative distribution functions" (CCDFs) that represent the probability of exceeding various levels of cumulative release caused by all significant processes and events" appears in 40 CFR 194.34 (p. 5242, Ref. 32) and implies that it is acceptable to omit FEPs from the PA calculations when there is a reasonable expectation that the resultant $\mathrm{CCDF}$ for cumulative release would not be significantly changed by such omissions).

The FEPs not screened out were retained for inclusion in the PA and were classified as undisturbed performance (UP) or disturbed performance (DP) FEPs. As an example, a summary of the screening process for natural FEPs is given in Table I; in addition, waste- and repository-induced FEPs (Table 6-4, Ref. 5) and human-initiated events and processes (EPs) (Table 6-5, Ref. 5) were also considered. A detailed description of the screening process is available in App. SCR of Ref. 5.

\section{EN1: Probabilistic Characterization of Different Futures}

The entity EN1 is the formal outcome of the FEPs process for determining what could happen at the WIPP. Specifically, EN1 provides a probabilistic characterization of the likelihood of different futures that could occur at the WIPP site over the 10,000 yr period specified in 40 CFR 191 . The entity EN1 is defined by a probability space $\left(S_{s l}, \delta_{s t}, p_{s t}\right)$, with the sample space $S_{s t}$ given by 
$S_{s t}=\left\{X_{s t}: X_{s t}\right.$ is a possible 10,000 yr sequence of occurrences at the WIPP $\}$.

The subscript $s t$ refers to stochastic (i.e., aleatory) uncertainty and is used because $\left(\mathcal{S}_{s t}, \delta_{s t}, p_{s t}\right)$ is providing a probabilistic characterization of occurrences that may take place in the future. ${ }^{40,41}$

The introduction of the idea of a probability space may seem overly formal. However, this introduction . provides a way to distinguish between the use of probability in the definition of EN1 (i.e., in the characterization of stochastic uncertainty) and the use of probability in the definition of EN3 (i.e., in the characterization of subjective uncertainty; see $\operatorname{Sect} 6)$. As a reminder, a probability space $(S, \delta p)$ consists of three components: a set $\delta$ that contains everything that could occur for the particular "universe" under consideration, a suitably restricted set $b$ of subsets of $\mathcal{S}$, and a function $p$ defined for elements of $b$ that actually defines probability. 42 In the terminology of probability theory, $S$ is the sample space; the elements of $S$ are elementary events; the subsets of $S$ contained in $\delta$ are events; and $p$ is a probability measure.

The FEPs development process for the WIPP identified drilling for natural resources as the only disruption with sufficient likelihood and consequence for inclusion in the definition of EN1 (App. SCR, Ref. 5). In addition, 40 CFR 194 specifies that the occurrence of mining within the land withdrawal boundary must be included in the analysis. The preceding considerations led to the elements $\mathrm{x}_{s t}$ of $\mathcal{S}_{s t}$ being vectors of the form

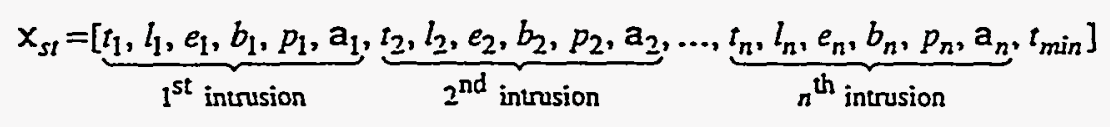

in the 1996 WIPP PA, where $n$ is the number of drilling intrusions, $t_{i}$ is the time (yT) of the $i^{\text {th }}$ intrusion, $l_{i}$ designates the location of the $i^{\text {th }}$ intrusion, $e_{i}$ designates the penetration of an excavated or nonexcavated area by the $i^{\text {th }}$ intrusion, $b_{i}$ designates whether or not the $i^{\text {th }}$ intrusion penetrates pressurized brine in the Castile Fm (see Sect. 2.2, Vol. 2, Ref. 4, for detailed stratigraphy), $p_{i}$ designates the plugging procedure used with the $i^{\text {th }}$ intrusion, $a_{i}$ designates the type of waste penetrated by the $i^{\text {th }}$ intrusion, and $t_{\min }$ is the time at which potash mining occurs within the land withdrawal boundary (Table $\mathrm{II}$ ).

With respect to the questions indicated in Sect. $2, \delta_{s t}$ provides an answer to Q1, while $\delta_{s t}$ and $p_{s t}$ provide an answer to Q2. In practice, Q2 is answered by the distributions specified for $n, t_{i}, l_{i}, e_{i}, b_{i}, p_{i}, a_{i}$ and $t_{\min }$ (Table III), which in concept lead to definitions for $\&_{s t}$ and $p_{s t}$. The CCDF specified in 40 CFR 191 is obtained by evaluating an integral involving $\left(\delta_{s t}, \delta_{s t}, p_{s t}\right)$ (Fig. 2), with the probabilities associated with $\&_{s t}$ and $p_{s t}$ being replaced symbolically by the corresponding density function $d_{s t}$. The function $f$ in Fig. 2 represents the environmental release associated with $X_{s t}$, corresponds to the second entity (i.e., EN2) in the 1996 WIPP PA, and is discussed in the next section. 


\section{EN2: Estimation of Releases}

The entity EN2 is the formal outcome of the FEPs process for determining what physical processes should be modeled at the WIPP, although most of the development of the mathematical representations for these physical processes took place outside of the FEPs process. Specifically, EN2 provides a way to estimate radionuclide releases to the accessible environment for the different futures (i.e., elements $X_{51}$ of $S_{s l}$ ) that could occur at the WIPP.. In concept, estimation of environmental releases comesponds to evaluation of the function $f$ in Fig. 2; in practicc. estimation of environmental releases and other system properties of interest involves evaluation of the models indicated in Fig. 3 and briefly described in Table IV.

When expressed in terms of the models indicated in Fig. 3 and Table IV, the function $f$ in Fig. 2 is given by

$$
\begin{aligned}
f\left(\mathbf{x}_{s t}\right)= & f_{C}\left(\mathbf{x}_{s t}\right)+f_{S P}\left[\mathbf{x}_{s t}, f_{B}\left(\mathbf{x}_{s t}\right)\right]+f_{D B R}\left\{\mathbf{x}_{s t}, f_{S P}\left[\mathbf{x}_{s t}, f_{B}\left(\mathbf{x}_{s t}\right)\right] f_{B}\left(\mathbf{x}_{s t}\right)\right\} \\
& +f_{M B}\left[\mathbf{x}_{s t}, f_{B}\left(\mathbf{x}_{s t}\right)\right]+f_{D L}\left[\mathbf{x}_{s t}, f_{B}\left(\mathbf{x}_{s t}\right)\right]+f_{S}\left[\mathbf{x}_{s t}, f_{B}\left(\mathbf{x}_{s t}\right)\right] \\
& +f_{S-T}\left\{\mathbf{x}_{s t, 0}, f_{S-F}\left(\mathbf{x}_{s t, 0}\right), f_{N-P}\left[\mathbf{x}_{s t}, f_{B}\left(\mathbf{x}_{s t}\right)\right]\right\},
\end{aligned}
$$

where $x_{s t}$ - particular future under consideration, $x_{51.0}$ - future involving no drilling intrusions but a mining event at the sarme time $t_{\min }$ as in $x_{s t}, f_{C}\left(X_{s t}\right)$ - cuttings and cavings release to accessible environment for $x_{s t}$ calculated with CUTIINGS_S, $f_{B}\left(x_{s t}\right)$ - results calculated for $x_{s t}$ with BRAGFLO (in practice, $f_{B}\left(x_{s t}\right)$ is a vector containing a large =mount of information), $f_{S P}\left[x_{s t}, f_{B}\left(x_{s t}\right)\right] \sim$ spallings release to accessible environment for $x_{s t}$ calculated with the spillings model contained in CUTTINGS_S (this calculation requires BRAGFLO results (i.e., $f_{B}\left(X_{s t}\right)$ ) as input), $f_{D B R}\left\{x_{s t}, f_{S P}\left[x_{s t}, f_{B}\left(x_{s t}\right)\right], f_{B}\left(x_{s t}\right)\right\}$ \& direct brine releasie to accessible environment for $x_{s t}$ calculated with a modifi:d version of BRAGFLO designated BRAGFLO_DBR (this calculation requires spallings results obtained from CUTTINGS_S (i.e., $\left.f_{S P}\left[\mathbf{x}_{s t}, f_{B}\left(\mathbf{x}_{s t}\right)\right]\right)$ and BRAGFLO results (i.e., $\left.f_{B}\left(\mathbf{x}_{s t}\right)\right)$ as input), $f_{M B}\left[\mathbf{x}_{s t}, f_{B}\left(\mathbf{x}_{s t}\right)\right]$ release through anhydrite marker beds to accessible environment for $x_{s t}$ calculated with NUTS (this calculation requires BRAGFLO results (i.e., $f_{B}\left(\mathbf{x}_{s t}\right)$ ) as input), $f_{D L}\left[\mathbf{x}_{s s}, f_{B}\left(\mathbf{x}_{s t}\right)\right]$ - release through Dewey Lake Red Beds to accessible environment for $x_{s t}$ calculated with NUTS (this calculation requires BRAGFLO results (i.e., $f_{B}\left(x_{s t}\right)$ ) as input), $f_{S}\left[x_{S I}, f_{B}\left(x_{S I}\right)\right]$ release to land surface due to brine flow up a plugged borehole for $x_{s t}$ calculated with NUTS cr PANEL as appropriate (this calculation requires BRAGFLO results (i.e., $f_{B}\left(x_{s t}\right)$ ) as input), $f_{S-F}\left(x_{s t, 0}\right)$ flow field calculated for $x_{s t, 0}$ with SECOFL2D, $f_{N-P}\left[x_{s t}, f_{B}\left(x_{s t}\right)\right]$ - release to Culebra for $x_{s t}$ calculated with NUTS or PANEL as appropriate (this calculation requires BRAGFLO results (i.e., $f_{B}\left(x_{s t}\right)$ ) as input), $f_{S-T}\left\{x_{-t .0}, f_{S-F}\left(x_{s t .0}\right), f_{N-P}\left[x_{s t}, f_{B}\left(x_{S t}\right)\right]\right\}$ - groundwater transport release through Culebra to accessible environment calculated with SECOTP2D (this calculation requires SECOFL2D results (i.e., $f_{S-F}\left(x_{s t .0}\right)$ ) and NUTS 
or P.ANEL resuls (i.e., $f_{N-P}\left[x_{s s} f_{B}\left(x_{s s}\right)\right]$ ) as input; $x_{s t, 0}$ is used as an argument to $f_{S-T}$ because drilling intrusions are assumed to cause no perturbations to the flow field in the Culebra).

The models in Fig. 3 and Table IV are 100 complex to permit a closed-form evaluation of the integral in Fig. 2 that defines the CCDF specified in 40 CFR 191. Instead, a Monte Carlo procedure was used in the 1996 WIPP PA. 59 With this approach, elements

$$
x_{s t, i, i} i=1,2, \ldots, n S \text {, }
$$

were randomly sampled from $\delta_{s t}$ in consistency with the definition of $\left(\delta_{s s}, \delta_{s t}, p_{s t}\right)$. Then, the integral in Fig. 2. and hence the associated CCDF, was approximated by

$$
\operatorname{prob}(\operatorname{Rel}>R)=\int_{S_{s t}} \delta_{R}\left[f\left(\mathrm{x}_{s t}\right)\right] d_{s t}\left(\mathrm{x}_{s t}\right) d V_{s t} \doteq \sum_{i=1}^{n S} \delta_{R}\left[f\left(\mathrm{x}_{s t, i}\right)\right] / n S,
$$

where $\delta_{R}\left[f\left(x_{s t}\right)\right]=1$ if $f\left(x_{s t}\right)>R$ and 0 if $f\left(x_{s t}\right) \leq R$. The Monte Carlo CCDF construction procedure indicated in Eq. (6) and implemented by CCDFGF program 60,61 used a sample of size $n S=10,000$ in the 1996 WIPP PA. The individual programs in Fig. 3 do not run fast enough to allow this number of evaluations of $f$. As a result, it was necessary to evaluate the programs in Fig. 3 for a limited number of futures and then to use this limited number of evaluations to construct the releases for the large number of futures that must be considered in Eq. (6) (see Sect. 7).

With respect to the questions indicated in Sect. 2, the models in Fig. 3 and Table IV are providing an answer to Q3.

\section{EN3: Probabilistic Charácterization of Parameter Uncertainty}

- The entity EN3 is the formal outcome of the data development effort for the WIPP. Specifically, EN3 provides a probabilistic characterization of the uncertainty in the parameters that underlie the WIPP PA. The entity EN3 is defined by a probability space $\left(\delta_{s u}, \mathcal{L}_{s u}, p_{s u}\right)$, with the sample space $\delta_{s u}$ given by

$$
S_{s u}=\left\{X_{s u}: X_{s u} \text { is possibly the correct vector of parameter values to use in the WIPP PA models }\right\} .
$$

The subscript su refers to subjective (i.e., epistemic) uncertainty and is used because $\left(\delta_{s u}, \delta_{s u}, p_{s u}\right)$ is providing a probabilistic characterization of where the appropriate inputs to use in the WIPP PA are believed to be located. 40,41 The vectors $x_{s u}$ in $\delta_{s u}$ are of the form

$$
x_{s u}=\left[x_{1}, x_{2}, \ldots, x_{n v}\right]
$$


where each element $x_{j}$ of $x_{s u}$ is an uncertain input to the 1996 WIPP PA and $n V$ is the number of such inputs (Table V).

The uncertainty in $x_{s u}$ is characterized by specifying a distribution

$$
D_{j}, j=1,2, \ldots, n V
$$

for each element $x_{j}$ of $x_{s u}$ (Fig. 4). Correlations and other restrictions involving the elements of $x_{s u}$ are also possible. In the 1996 WIPP PA, rank correlations63,64 were imposed on three pairs of variables (Fig. 5). The distributions $D_{j}$, $j=1,2, \ldots, n V$, and any associated conditions then give rise to the probability space $\left(S_{s u}, \delta_{s u}, p_{s u}\right)$.

In concept, individual elements of $x_{s u}$ can affect either the definition of $\left(\mathcal{S}_{s t}, \delta_{s t}, p_{s t}\right)$ or the definition and/or evaluation of $f$. For example, the drilling rate or probability of penetrating pressurized brine in the Castile Fm could be treated as being uncertain, which would affect the definition of $\left(S_{s t}, \delta_{s t}, p_{s t}\right)$. Similarly, whether to use the Brooks-Corey or van Genuchten-Parker model for relative permeability or the appropriate value of a spatiallyaveraged distribution coefficient (i.e., $k_{d}$ value) could be treated as being uncertain, with the former affecting the definition of $f$ and the latter defining a specific input parameter to $f$. All elements of $x_{s u}$ relate to the models in Fig. 2 in the 1996 WIPP PA. However, this does not have to be the case, and the probability of penetrating pressurized brine (i.e., $p B_{1}$ in Table II) was treated as being uncertain in a verification analysis associated with the 1996 WIPP PA carried out by SNL for the EPA. ${ }^{65}$

If $x_{s u}$ was known exactly, then the CCDF in Fig. 2 could be determined with certainty and an unambiguous comparison made with the boundary line specified in 40 CFR 191. However, given the complex physical processes that could take place at the WIPP site and the 10,000 yr time period under consideration, $x_{s u}$ can never be known with certainty. Instead, uncertainty in $x_{s u}$ as characterized by $\left(\mathcal{S}_{s u}, b_{s u}, p_{s u}\right)$ will lead to a distribution of possible CCDFs (Fig. 6), with a different CCDF resulting for each value that $x_{s u}$ can take on. As indicated in Fig. 6, $f$ is now being viewed as a function of both $x_{s t}$ and $x_{s t}$, with $\left(\mathcal{S}_{s t}, \delta_{s t}, p_{s t}\right)$ giving rise to a different CCDF for each value that $x_{s u}$ can take turn. In turn, $\left(\mathcal{S}_{s u 2} \delta_{s u}, p_{s u}\right)$ gives rise to a distribution of CCDFs. The proximity of this distribution to the boundary line in Fig. 2 provides an indication of the confidence with which 40 CFR 191 will be met.

The distribution of CCDFs in Fig. 6 can be summarized by distributions of exceedance probabilities conditional on individual release values (Fig. 7). For a given release value $R$, this distribution is defined by a double integral over $S_{s u}$ and $S_{s t} 41,66$ In practice, this integral is too complex to permit a closed-form evaluation. Instead, the 1996 , WIPP PA used Latin hypercube sampling ${ }^{62}$ to evaluate the integral over $S_{s u}$ and, as indicated in Eq. (6), simple random sampling to evaluate the integral over $S_{s t}$. With this approach, a Latin hypercube sample (LHS) $x_{s u, k}, k=1$, $2, \ldots, n L H S$, is generated from $\mathcal{S}_{s u}$ in consistency with the definition of $\left(\mathcal{S}_{s u}, \delta_{s u}, p_{s u}\right)$, and a random sample $\mathrm{x}_{s t, i}, i=$ 
$1,2, \ldots, n S$, is generated from $S_{s l}$ in consistency with the definition of $\left(S_{s t}, b_{s,}, p_{s t}\right)$. The percentile values in Fig. 7 are then approximated by solving

$$
\operatorname{prob}(p \leq P \mid R) \doteq 1-\sum_{k=1}^{n L H S} \delta_{P}\left[\sum_{i=1}^{n S} \delta_{R}\left[f\left(\mathrm{x}_{s t, i}, \mathrm{x}_{s u, k}\right)\right] / n S\right] / n L H S
$$

for $P$ with $\operatorname{prob}(p \leq P \mid R)=0.1,0.5$ and 0.9 , respectively, and the definition of $\delta_{R}$, and hence the corresponding definition of $\delta_{P}$, given in conjunction with Eq. (6). Similarly, the mean exceedance probability $\bar{P}$ is approximated by

$$
\vec{P} \doteq \sum_{k=1}^{n L H S}\left[\sum_{i=1}^{n S} \delta_{R}\left[f\left(x_{s t, i}, x_{s u, k}\right)\right] / n S\right] / n L H S .
$$

The results of the preceding calculations are typically displayed by plotting percentile values (e.g., $P_{0.1}, P_{0.5}, P_{0.9}$ in Fig. 7) and also mean values for exceedance probabilities (i.e., $\bar{P}$ in Fig. 7) above the corresponding release values (i.e., $R$ ) and then connecting these points to form continuous curves (Fig. 8). The proximity of these curves to the indicated boundary line provides an indication of the confidence with which 40 CFR 191 will be met.

With respect to the questions indicated in Sect. $2,\left(\mathcal{S}_{s u}, \delta_{s u}, p_{s u}\right)$ and results derived from $\left(\mathcal{S}_{s u}, \delta_{s u}, P_{s u}\right)(\mathrm{e} . \mathrm{g} .$, the distributions in Figs. 6-8) are providing an answer to $Q 4$.

\section{Computational Details of 1996 WIPP PA}

The requirements in 194.34(c), (d) and (f) relate to the procedures used for a Monte Carlo integration over $\left(\mathcal{S}_{s u}\right.$, $\left.\delta_{s u}, p_{s u}\right)$. The accuracy requirements in 194.34 (d) can be satisfied with a simple random sample from $\delta_{s u}$ of size 300 (i.e., $1-0.99^{n}>0.95$ yields $n=298$ ). However, the 1996 WIPP PA decided to use Latin hypercube sampling ${ }^{62}$ rather than simple random sampling for the required Monte Carlo integration on $\left(\mathcal{S}_{s u}, \delta_{s u}, p_{s u}\right)$ due to the efficient stratification properties of Latin hypercube sampling. $.67-69$

By using an LHS of size 300, the requirements in 194.34(c) and (d) can be met. Further, the confidence intervals required in 194.34(f) can be determined by generating the LHS with a replicated sampling procedure proposed by R.I. Iman. 70 In this procedure, the LHS $x_{s u ' k}, k=1,2, \ldots, n L H S$, used in Eqs. (10) and (11) is repeatedly generated with different random seeds. These samples lead to a sequence $\bar{P}_{r}(R), r=1,2, \ldots, n R$, of estimated mean exceedance probabilities, where $\bar{P}_{r}(R)$ defines the mean CCDF obtained for sample $r$ (i.e., $\bar{P}_{r}(R)$ is the mean probability that a normalized release of size $R$ will be exceeded) and $n R$ is the number of independent LHSs generated with different random seeds. Then, 


$$
\bar{P}(R)=\sum_{r=1}^{n R} \bar{P}_{r}(R) / n R
$$

and

$$
S E(R)=\left\{\sum_{r=1}^{n R}\left[\bar{P}_{r}(R)-\bar{P}(R)\right]^{2} / n R(n R-1)\right\}^{1 / 2} \cdot
$$

provide an additional estimate of the mean CCDF and an estimate of the standard error associated with the mean exceedance probabilities. The $t$-distribution with $n R-1$ degrees of freedom can be used to place confidence intervals around the mean exceedance probabilities for individual $R$ values (i.e., around $\bar{P}(R)$ ). Specifically, the $1-\alpha$ confidence interval is given by $\bar{P}(R) \pm t_{1-\alpha / 2} S E(R)$, where $t_{1-\alpha / 2}$ is the $1-\alpha / 2$ quantile of the $t$-distribution with $n R-1$ degrees of freedom (e.g., $t_{1-\alpha / 2}=4.303$ for $\alpha=0.05$ and $n R=3$ ).

To implement the preceding procedure, the 1996 WIPP PA used $n R=3$ replicated LHSs of size $n L H S=100$ each. This produced a total of 300 observations, which is approximately the same as the sample size of 298 indicated above. Each sample has the form

$$
x_{s u, k}=\left[x_{k 1}, x_{k: 2}, \ldots, x_{k, n v}\right], k=1,2, \ldots, n L H S=100,
$$

and was generated with the restricted pairing technique developed by Iman and $\operatorname{Conover}^{63}$ to induce specified rank correlations between correlated variables and also to assure that uncorrelated variables have correlations close to zero.

The calculations performed with the models in Fig. 3 and Table IV for the LHS elements in Eq. (14) had to be chosen very carefully. Otherwise, the total computational cost would have been prohibitive. In particular, a full set of model calculations to determine $f\left(x_{s t, i}\right)$ in Eq. (6) could not be performed for each randomly-sampled future $x_{s t, i}$. Rather, calculations were performed for a selected group of futures for each LHS element (Table VI), and then various interpolations and algebraic procedures were used to extend the results obtained with these futures to the large number of randomly-sampled futures used in Eq. (6) (Chapts. 9-13, Ref. 44). As an example, the procedures used to construct the spallings release (i.e., $f_{S P}\left(x_{s t, i}\right)$ in Eq. (4)) will be described in Sect. 9; in addition, Sect. 6.6 of Ref. 44 provides a detailed description of the procedure used to sample the individual futures. Once values for $f\left(x_{s t, i}\right)$ were determined, which conespond to the normalized release $R$ in Eq. (1), the CCDF specified in 191.13(a) was readily constructed. Similarly, $\bar{f}_{C}, f_{S P}, f_{D B R}, f_{M B}, f_{D L}, f_{S}$ and $f_{S-T}$ in Eq. (4) were used to estimate CCDFs for individual release modes. 
Repetition of the preceding procedure for each LHS element yielded a distribution of CCDFs of the form in Fig. 8 for each of the $n R=3$ replicates as requested in 194.34 (e). Further, the replicated samples and the procedurc in Eqs. (12) and (13) provided a basis for the estimation of confidence intervals as requested in 194.34( $)$.

\section{Intermediate Results}

As indicated in Table VI, a large number of mechanistic calculations were performed as part of the 1996 WIPP PA. In turn, the outcomes of these calculations served as input to other mechanistic calculations or to algebraic procedures used in CCDF construction. The outcomes of a small number of these calculations are now presented. with more detailed presentations available in the original documentation for the 1996 WIPP PA (Refs. 44, 47, 48. $51,53,54,58)$.

The first result required in the evaluation of $f\left(x_{s t}\right)$ in Eq. (4) is the cuttings and cavings release (i.e., $f_{C}$ ). The volume of waste removed by cuttings and cavings was calculated by CUTTINGS_S (Fig. 9). As indicated in conjunction with $a_{i}$ in Table III, this volume was then multiplied by an appropriate radionuclide concentration to obtain the actual radionuclide release to the surface. The sampling of the waste type (see $a_{i}$ in Table III) and the individual waste streams if $\mathrm{CH}$ waste is peneurated is carried out within the Monte Carlo construction of individual CCDFs indicated in Eq. (6), with the cuttings and cavings release being dominated by intrusions through $\mathrm{CH}$ waste. In particular, the average concentration of $\mathrm{CH}$ waste is higher than that of $\mathrm{RH}$ waste (Fig. 10), and a drilling intrusion is more likely to penetrate $\mathrm{CH}$ waste than $\mathrm{RH}$ waste (se $p C H$ and $p R H$ in entry for $\mathrm{a}_{i}$ in Table III). Further. the variation in the radionuclide concentrations in the 569 waste streams for $\mathrm{CH}$ waste causes a wide range in the size of the releases associated with individual drilling intrusions through $\mathrm{CH}$ waste (Fig. 11).

The BRAGFLO model (i.e., $f_{B}$ in Eq. (4)) produced results used by CUTTINGS_S, BRAGFLO_DBR, NUTS and PANEL to estimate releases from the repository. An important result supplied by BRAGFLO and used by CUTTINGS_S and BRAGFLO_DBR to estimate spallings and direct brine releases, respectively, is repository pressure (Fig. 12). The pressure results in Fig. 12 are for replicate RI and BRAGFLO calculations for two cases: (i) undisturbed (i.e., E0) conditions and (ii) a drilling intrusion at $1000 \mathrm{yr}$ that penetrates pressurized brine in the Castile $\mathrm{Fm}$ (i.e., an EI intrusion at $1000 \mathrm{yr}$ ). Each frame in Fig. 12 contains 100 individual pressure curves, with each curve calculated for one of the 100 LHS elements associated with replicate R1 (see Eq. (14)). Thus, Fig. 12 displays results (i.e., pressure curves) obtained in 200 of the 1800 calculations performed with BRAGFLO (Table VI).

The pressure in the repository under undisturbed conditions tends to increase monotonically toward an asymptote (Fig. 12a). In contrast, pressure tends to drop rapidly subsequent to a drilling intrusion due to gas flow up the borehole (Fig. 12b). Due to the relatively high permeability of the repository and the surrounding disturbed rock 
zone (DRZ), pressure gradients within the repository are small and pressure is almost constant throughout the repository at any given time.

Spallings results (i.e., $f_{S P}$ in Eq. (4)) were calculated for both drilling intrusions into an undisturbed repository (i.e., E0 conditions) and drilling intrusions subsequent to an E1 or E2 intrusion (Table VI), with intrusions under. undisturbed (Fig. 13) and disturbed (Fig. 14) repository conditions using pressure results of the form shown in Figs. $12 \mathrm{a}$ and $12 \mathrm{~b}$, respectively. Repository pressure at the time of the intrusion is used in the calculation of spallings releases with CUTTINGS_S. The calculations with CUTTINGS_S produced volumes of material released due to spallings (Figs. 13a, 14a), with these volumes then multiplied by the concentration of radionuclides in waste (EPA units/ $\mathrm{m}^{3}$ as d.:fined in Eq. (1)) (Fig. 10) to produce radionuclide releases to the surface (Figs. 13b, 14b). Second and subsequent dilling intrusions often produce no spallings release (Fig. 14) due to low pressure in the repository (Fig. 12b). In particular, a column of drilling fluid at the depth of the repository exerts a pressure of approximately 8 $\mathrm{MPa}$, and so both spallings releases and direct brine releases were assumed to have the potential to take place only when the pres iure in the repository was above $8 \mathrm{MPa}^{48}$

Direct brine releases (i.e., $f_{D B R}$ in Eq. (4)) were calculated for the same cases as spallings releases (Table VI). Similarly to the spallings calculation with CUTTINGS_S, a brine release was initially calculated by BRAGELO_LBR (Fig. 15a), which was then multiplied by a radionuclide concentration (Fig. 16) to produce a direct brine release to the surface (Fig. 15b). Time-dependent radionuclide concentrations for Salado-dominated brine (Fig. 16a) and Castile dominated brine (Fig. 16b) were used in the analysis because the chemistry of the brine and hence radionuclide solubilities are believed to be a function of brine source. The distributions of concentration curves in Fig. 16 result from uncertain variables contained in $x_{s u}$ and sampled in the LHS in Eq. (14). The calculations for direct brine releases subsequent to an initial drilling intrusion have the same case structure as for spallings releases (Table VI), with these releases often being zero due to either low pressure or low brine saturation in the repository (Figs. 10.1.6, 10.1.7, Ref. 44).

Another inportant result calculated by BRAGFLO is brine flow away from the repository, with such flows then used as input ti) NUTS and PANEL to determine radionuclide transport away from the repository by flowing brine. In terms of the representation for $f\left(x_{s t}\right)$ in Eq. (4), these flows are used in the determination of $f_{M B}, f_{D L}, f_{S}$ and $f_{N-P}$. The releases rejresented by $f_{M D}, f_{D L}$ and $f_{S}$ were determined by calculations performed with NUTS and were found to be zero for each of the 1500 BRAGFLO calculations used to supply input for NUTS calculations (Table VI) due to limited or nonexistent brine flow from the repository to the marker beds, the Dewey Lake Red Beds and the land surface. The only potentially significant brine flows away from the -repository calculated by BRAGFLO were up an intruding borehole from the repository to the Culebra Dolomite (Fig. 17), with these flows used in the determination of $f_{N-P}$ with NUTS or PANEL as appropriate (Table VD). However, most of these potentially important flows were also zero or very close to zero (Fig. 17). 
The NUTS program was used to determine $f_{N^{-}-p}$ for cases involving a single drilling intrusion (i.c.. an $\mathrm{El}$ or $\mathrm{E} 2$ intrusion), and the PANEL program was used to determine $f_{N^{-}-P}$ for cases involving both an E2 and an El intrusion into the same waste panel (i.e., an E2EI intrusion). As an example, Fig. 18 shows releases of individual radionuclides for an $E_{1}$ intrusion at $1000 \mathrm{yr}$ (Fig. 18a) and total normalized releases for $E l$ intrusions at different times (Fig. 18b). The large number of zero releases are resulting from a failure of the repository to fill with brine. with the result that there is no brine flow from the repository to the Culebra. The results in Fig. 18 are cumulative (i.e.. integrated) releases. As an example, the time-dependent cumulative releases for an El intrusion at 1000 yr are show' in Fig. 19, with the cumulative releases at 10,000 yr corresponding to the total normalized releases for replicate RI and an intrusion at 1000 yr in Figs. 18a and $18 \mathrm{~b}$.

The releases to the Culebra calculated by NUTS and PANEL provided input to SECO2DTP for transport through the Culebra to the accessible environment (i.e., for the evaluation of $f_{S-T}$ in Eq. (4)). Also. Culebra flow fields were provided by calculations performed with SECO2DFL. The actual results available from NUTS and PANEL were time-dependent release rates of individual radionuclides to the Culebra (i.e., results of the form that were integrated to obtain the cumulative releases in Fig. 19 but for individual radionuclides).

To save on computational requirements, the 1996 WIPP PA performed SECO2DTP calculations for unit radionuclide releases to the Culebra, with the results of these calculations then being used to construct transport results for arbitrary time-dependent radionuclide releases to the Culebra (Table 12.2.3, Ref. 44). This computational strategy was possible because SECO2DTD is based on the solution of a system of linear partial differential equations. When the SECO2DTP calculations were performed for unit releases to the Culebra, the resultant transport to the accessible environment was found to be zero for all sample elements and all radionuclides except for [i-234 for one sample element. However, that sample element had no radionuclide release to the Culebra. Thus, although radionuclide releases to the Culebra did take place for some sample elements, no radionuclide transpor through the Culebra to the accessible environment took place in the analysis.

\section{Construction of CCDFs and Comparisons with 40 CFR 191.13}

The central result calculated in the 1996 WIPP PA is the CCDF for normalized radionuclide release to the accessible environment specified in 40 CFR 191.13 (Sect. 2). As indicated in Sects. 4 and 5, individual CCDFs were constructed with Monte Carlo techniques for normalized releases defined by a function $f$ of the form in Eq. (4), with such CCDFs characterizing the effects of stochastic uncertainty. Further, as indicated in Sects. 6 and 7 , distributions of CCDFs derive from subjective uncertainty and were estimated with procedures based on Latin hypercube sampling.

Of the components of $f$ in Eq. (4), only $f_{C}, f_{S P}$ and $f_{D B R}$ are nonzero in the 1996 WIPP PA, with the result that $f$ has the simpler form 


$$
f\left(x_{s l}\right)=f_{C}\left(x_{s l}\right)+f_{S P}\left[x_{s l}, f_{B}\left(x_{s t}\right)\right]+f_{D B R}\left\{x_{s r} \cdot f_{S P}\left[x_{s I}, f_{B}\left(x_{s l}\right)\right] \cdot f_{B}\left(x_{s l}\right)\right\}
$$

Although the CCDF specified in 40 CFR 191.13 is for all release modes (i.e.. is based on $f$ as defined in Eqs. $(t)$ and (15)). CCDFs can also be determined for the individual release modes (i.e., $f_{C}, f_{S P}$ and $f_{D B R}$ in Eq. (15)). with such results helping provide perspective on what is determining the location of the CCDF for all release modes.

As an example, the construction of the CCDFs associated with spallings releases is now illustrated. This construction is based on the evaluation of $f_{S P}\left(x_{s t . i}\right)$ for a sequence of randomly sampled futures $x_{s t . i,} i=1,2 \ldots$. $n S=10,000$ (sec Eqs. (5), (6)). Specifically, the construction uses resuits obtained in a small number of calculations performed with CUTTINGS_S (Table VII) in conjunction with algebraic manipulations and interpolations (Table VIII) to estimate $f_{S P}\left(\mathbf{x}_{s t, i}\right)$ for each randomly sampled future $x_{s t, i}$. Once the $f_{S P}\left(x_{s t . i}\right)$ are evaluated, the resultant CCDF can be constructed as indicated conceptually in Eq. (6), although in computational practice a somewhat different and more efficient procedure is used (Sect. 6.7, Ref. 44). The computational results described in Table VII are illustrated in Figs. 10,13 and 14. The distributions in Figs. 13 and 14 are over all 300 LHS elements used in the analysis. However, the algorithm described in Table VIII to determine $f_{S P}\left(X_{s s, i}\right), i=1,2, \ldots, n S$, uses results obtained with one LHS element at a time (i.e., $x_{s u . k}$ in Eq. (14)), with the result that each constructed CCDF is conditional on the occurrence of a specific LHS element.

The resultant distribution of CCDFs for the spallings release for replicate $\mathrm{R} 1$ is shown in Fig. 20b. As each CCDF was constructed for a single LHS element, Fig. $20 \mathrm{~b}$ potentially contains $100 \mathrm{CCDFs}$, although only $\delta 2$ CCDFs appear in the plot because $18 \mathrm{LHS}$ elements failed to produce spallings releases that exceeded $1 \times 10^{-5} \mathrm{EPA}$ units. The spread of the CCDFs in Fig. 20b is providing an indication of confidence that the CCDF for spallings release does indeed fall below the boundary line specified in 40 CFR 191.13. As indicated by the location of all CCDFs to the left of the boundary line $x_{x}$ high degree of confidence exists that the CCDF for spallings releases meets the requirements imposed by 40 CFR 191.13.

Similar construction procedures were also used to determine CCDFs due to cuttings and cavings (Sect. 9.2. Ref. 44) and direct brine releases (Sect. 10.3, Ref. 44). Further, the cuttings and cavings, spallings and direct brine releases were combined to determine a total release as indicated in Eq. (15). The CCDFs for the individual release modes and the total release fall substantially to the left of the boundary line specified in 40 CFR 191.13, with the total release dominated by the cuttings and cavings component (Fig. 20).

The presentation of mean CCDFs and percentile curves as described in conjunction with Fig. 8 provides a more quantitative way to compare the distributions of CCDFs in Fig. 20 with the boundary line specified in 40 CFR 191.13. As an example, mean and percentile curves for the total release are shown in Fig. 21 and fall substantially to the left of the boundary line. 
The curves in Fig. 21 were oblained by pooling replicates R1. R2 and R3 (i.e.. the mean CCDFs and percentile curves were constructed from the $300 \mathrm{CCDF}$ associated with replicates R1, R2 and R3). Howcver, the resul(s obtained with the individual replicates were quite stable, with litle variation in the location of the mean CCDF and percentile curves from replicate to replicate. For the total release CCDFs, the results obtained with the individual replicates are almost indistinguishable (Fig. 22a).

The requirement in 40 CFR 194.34(f) mandates the determination of a $95 \%$ confidence interval on the mean CCDF (Sect. 2), which can be obtained from the three replicated samples with the technique described in conjunction with Eqs. (12) and (13). In particular, a very tight confidence interval exists around the mean CCDF (Fig. 22b), which is consistent with the stability of the mean CCDF across the three replicates (Fig. 22a).

\section{Discussion}

The 1996 WIPP PA was carried out to support an application by the DOE to the EPA for the certification of the WIPP for the disposal of TRU waste. ${ }^{5}$ The most important result from a regulatory perspective calculated in this PA is a CCDF for normalized radionuclide release to the accessible environment, which is required to fall to the left of the boundary line specified in the EPA's regulation 40 CFR 191.13 (Sect. 2). Even when the effects of subjective uncertainty are taken into account, this CCDF was found to meet the requirements associated with 40 CFR 191.13 (Sect. 9).

Some individuals feel that the boundary line specified in 40 CFR 191.13 for the CCDF for normalized radionuclide release to the accessible environment (Fig. 2) is a novel concept. However, this boundary line is actually an example of the Farmer limit line approach to the definition of acceptable risk. ${ }^{72-74}$ A similar construction appears in the U.S. Nuclear Regulatory Commission's proposed large release safety goal (Fig. 20, Ref. 40; Refs. 75, 76).

As is typical of large PAs, the 1996 WIPP PA was not a single isolated analysis but rather the final outcome of a sequence of iterative PAs carried out over approximately 10 years.3.4. 24-26 By starting the PA process early in the development of the WIPP's CCA, important insights were obtained with respect to model and data needs and also with respect to the appropriate conceptual and computational structure of the PA itself. It is strongly recommended that any project that is required to produce a PA start the process as early as possible so that the associated experience and insights can be gained before carrying out the final PA.

The overall conceptual and computational structure of the 1996 WIPP PA derived from the requirement to maintain a separation between stochastic (i.e., aleatory) uncertainty and subjective (i.e., epistemic) uncertainty as mandated in 40 CFR 191 and 40 CFR 194 (Sect. 2). This distinction was maintained by defining separate probability spaces $\left(S_{s l}, b_{s l}, p_{s l}\right)$ and $\left(S_{s u}, \delta_{s u}, p_{s u}\right)$ for stochastic and subjective uncertainty, respectively, with 
individual CCDFs for comparison with the boundary line in 40 CFR 191.13 deriving from stochastic uncertainty and distributions of CCDFs deriving from subjective uncertainty (Sects. 4-6). In the computational implementation of the PA. simple random sampling was used to determine the effects of stochastic uncertainty. and Latin hypercuhe sampling was used to determine the effects of subjective uncertainty (Sects. 7-9).

The use of simple random sampling to asseșs the effects of stochastic uncertainty was made possible br performing a relatively small number of mechanistic calculations for each LHS element (Tables VI. VII) and then using algebraic procedures. (Table VIII) to extend the results of these calculations to the large number of futures generated in random sampling from the probability space $\left(\delta_{s t}, \delta_{s i}, p_{s t}\right)$. The maintenance of an appropriate separation between stochastic and subjective uncertainty, as done in the 1996 WIPP PA, is widely recognized as an essential part of PAs for complex systems. ${ }^{40,41.77-81}$

Formal quality assurance (QA) procedures are essential in an analysis such as the 1996 WIPP PA that supports a major regulatory decision and, indeed, are specified by the EPA as part of the requirements that must be satisfied by: the WIPP (see Sect. 194.22, Ref. 32, which specifies adherence to a QA program that implements the requirements of ASME NQA-1, ASME NQA-2a and ASME NQA-3). Such procedures assure (i) adequate documentation of models and the computer programs that implement them, (ii) adequate documentation of analysis assumptions and data used within the analysis, and (iii) the traceability and archival storage of all calculations performed as part of the analysis. To this end, formal QA procedures based on guidance from the $\mathrm{EPA}^{32}$ and the $\mathrm{DOE}^{82}$ were implemented and followed as an integral part of the 1996 WIPP PA.

Although not emphasized in this presentation, regression-based sensitivity analysis played an important role in both the 1996 WIPP PA 44 and in earlier PAs (Vol. 4, Ref. 3; Vols. 4, 5, Ref. 4; Refs. 27-29, 83, 84) and helped provide many of the important insights gained in these PAs. In particular, the LHSs used to propagate subjective uncertainty lead to a mapping from uncertain analysis inputs to analysis results that can be explored with techniques based on examination of scatterplots, stepwise regression analysis and partial correlation analysis. ${ }^{85}$ Sensitivity analysis provides a way to identify which of the uncertain inputs to the analysis (Table $V$ ) are most imponant in determining the uncertainty in analysis outcomes. For example, the uncertainty characterized by the distribution of CCDFs in Fig. 20d for total normalized release to the accessible environment is dominated by the uncertainty in the shear strength of the waste (WTAUFAIL in Table V) and the extent to which microbial degradation of cellulose takes place (WMICDFLG in Table V), with smaller effects due to a number of additional variables (Sect. 13.2, Ref. 44). Further, sensitivity analysis constitutes a powerful tool for analysis verification by providing a way to examine the effects.of different inputs on a large number of analysis outcomes, with the possibility of an error being indicated when a variable has an observed effect that is not consistent with its anticipated effect (e.g., the observation that radionuclide release to the Culebra increases as radionuclide solubility decreases would suggest that there was probably an error in the implementation of the analysis). 
The EPA has proposed ccrtification of the WIPP for the disposal of TRU uaste. St and at prescri (Fchruary 1998), it appears likely that the WIPP will be in operation by the end of 1998. The LWA21 specifies that the WIPP must undergo a recentification every five years. These recertifications will requirc updates of the CCA PA descrited in this presentation that incorporate any new information or perspectives with respect to the WIPP that have been acquired since the implementation of this PA.

\section{Acknowledgment}

Work performed for Sandia National Laboratories (SNL), which is a multiprogram laboratory operaled by Sandia Corporation, a Lockheed Martin Company, for the United States Department of Energy under contract DE-AC04-94AI-85000. Many individuals at SNL and its contractors contributed to the results in this presentation. including K. Aragon, J.E. Bean, D.G. Bennet, J.W. Berglund, R. Blaine, M.B. Crawford, F.J. Davis, K. Economy, D. A. Galson, J.W. Garner, F.D. Hansen, T.W. Hicks, J.D. Johnson, M.K. Knowles. K.W. Larson, M.E. Lord. R.J. MacKinnon, J. Miller, D.G. O'Brien, J.L. Ramsey, L.C. Sanchez, J. Schatz. J.D. Schreiber. A. Shinta, L.N. Smith, D.M. Stoelzel, C. Stockman, P.N. Swif, T.W. Thompson, M.S. Tiernej, P. Vaughn. M. Wallace. M. Williamson, and R.D. Wilmot. Review provided at SNL by M. Chavez, C. Crauford and M.J. Shonencarier. Editorial support provided by L. Harrison, T. Allen, and H. Olmstead of Tech Reps. Inc.

\section{References}

1. U.S. Department of Energy, Final Environmental Impact Statement: Waste Isolation Pilot Plant, DOE/EIS= 0026 (Office of Environmental Restoration and Waste Management, Washington, DC, 1980).

2. U.S. Department of Energy, Final Supplement: Environmental Impact Siatement. Waste Isolation Pilot Plant, DOE/EIS-0026-FS (Office of Environmental Restoration and Waste Management, Washington. DC, 1990).

6

3. WIPP Performance Assessment Division, Preliminan' Comparison with 40 CFR Par 191. Subpan B for the Waste Isolation Pilot Plant, December 1991, Volumes 1-4, SAND91-0893/1-4 (Sandia National Laboratories, Albuquerque, NM, 1991-1992).

4. WIPP Performance Assessment Department, Preliminary Performance Assessment for the Waste Isolation Pilot Plant, December 1992, Volumes 1-5, SAND92-0700/1-5 (Sandia National Laboratories, Albuquerque, NM. 1992-1993).

5. U.S. Deparment of Energy, Title 40 CFR Pant 191 Compliance Cerification Application for the Waste Isolation Pilor Plant, DOE/CAO-1996-2184 (U.S. Deparment of Energy, Carisbad Area Office, Carlsbad, NM. 1996).

6. R.P. Rechard, An Introduction to the Mechanics of Performance Assessment Using Examples of Calculations Done for the Waste Isolation Pilot Plant between 1990 and 1992, SAND93-1378 (Sandia National Laboratories, Albuquerque, NM, 1995).

7. National Academy of Sciences/National Research Council, The Disposal of Radioactive Waste on Land: Repon of the Committee on Waste Disposal of the Division of Earth Sciences, Publication 519 (National Academy of Sciences/National Research Council, Washington, DC, 1957). 
8. R.L. Bradshaw and W.C. MeClain. Project Salt Vault: A Demonstration of the Disposal of High-Activin. Solidificd Waste in Underground Salt Mines, ORNL-4555 (Oak Ridge National Laborators, Oak Ridge. TN. 1971).

9. L.J. Carter, Nuclear Imperatives and Public Trust: Dealing with Radioactive Waste (Resources for the Future. Inc, Washington, DC, 1987).

10. National Academy of Sciences/National Research Council, Review of the Scientific and Technical Critcrin for . the Waste Isolation Pilot Plant (WIPP), DOEDP/48015-1 (National Academy Press, Washington. DC. 1984).

11. D.W. Powers et al., eds, Geological Characterization Repor, Waste Isolation Pilot PLant (WIPP) Sitc. Southeastem New Mexico, Volumes 1-2, SAND78-1596 (Sandia National Laboratories, Albuquerque, NM. 1978).

12. Public Law 91-190, National Environmental Polic) Act of 1969 (83 Stat. 852; 42 U.S.C. 1801 et seq.) (1970).

13. W.D. Wearh "WIPP: A Bedded Salt Repository for Defense Radioactive Waste in Southeastern New Mexico." Radioactive Waste in Geologic Storage, I76th Annual Meeting of the American Chemical Societ); Miami. Beach, FL, September 11-15, 1978, pp. 13-36, Ed. S. Fried, ACS Symposium Series No. 100 (American Chemical Society, Washington, DC, 1979).

14. Public Law 96-164, Department of Energy National Security and Military Applications of Nuclear Energy: Authorization Act of 1980 (1979).

15. U.S. Department of Energy and State of New Mexico, "Agreement for Consultation and Cooperation on WIPP by the State of New Mexico and U.S. Deparment of Energy" (U.S. Department of Energy, Albuquerque, NM, 1981).

16. U.S. Department of Energy, Summan' of the Results of the Evaluation of the WIPP Site and Preliminan. Design Validation Program, WIPP-DOE-161 (U.S. Deparment of Energy, Albuquerque, NM, 1983).

17. U.S. Department of Energy, "Announcement of Decision to Proceed with Construction of the Waste Isolation Pilot Plant (WIPP)," Federal Register 48, 30427-30428 (1983).

18. A.R. Lappin, Summany of Site-Characterization Studies Conducted from 1983 through 1987 at the Waste Isolation Pilot Plant (WIPP) Site,'Southeastern New Mexico, S.AND88-0157 (Sandia National Laboratories, Albuquerque, NM, 1988).

19. L.D. Tyler et al., Summan' Report for the WIPP Technology Development Program for Isolation of Radioactive Waste, SAND88-0844 (Sandia National Laboratories, Albuquerque, NM, 1988).

20. R.W. Lynch et al., Deep Geologic Disposal in the United States: The Waste Isolation Pilot Plant and Yucca Mountain Projects, SAND90-1656 (Sandia National Laboratories, Albuquerque, NM, 1991).

21. Public Law 102-579, Waste Isolation Pilot Plant Land Withdrawal Act (106 Stat. 4777) (1992).

22. U.S. Environmental Protection Agency, "Environmental Standards for the Management and Disposal of Spent Nuclear Fuel, High-Level and Transuranic Radioactive Wastes; Final Rule, 40 CFR Part 191," Federal Register 50, 38066-38089 (1985).

23. S.G. Bertram-Howery et al., Draft Forecast of the Final Report for the Comparison to 40 CFR Part 191. Subpan B, for the Waste Isolation Pilot Plant, SAND88-1452 (Sandia National Laboratories, Albuquerque, NM, 1989). 
24. M.G. Marietta et al., Perjomance-Assessment Methodology Demonstration: Methodology Development for Evaluating Compliance with EPA 40 CFR 191. Subpart B, for the Waste Isolation Pilot Plant, SANDS9-2027 (Sandia National Laboratories, Albuquerque, NM, 1989).

25. A.R. Lappin et al., Systems Analysis, Long-Term Radionuclide Transport, and Dose Assessments, Wostc Isolation Pilot Plant (WIPP). Southeastern New Merico; March 1989. SAND89-0462 (Sandia National Laboratories, Albuquerque, NM, 1989).

26. S.G. Bertram-Howery et al., Preliminary Comparison with 40 CFR Part 191. Subpart B for the Waste Isolation Pilot Plant, December 1990, SAND90-2347 (Sandia National Laboratories, Albuquerque, NM, 1990).

27. J.C. Helton et al., "Uncenainty and Sensitivity Analysis Results Obtained in a Preliminary Performance Assessment for the Waste Isolation Pilot Plant," Nuclear Science and Engineering 114, 286-331 (1993).

28. J.C. Helton et al., "Effect of Alternative Conceptual Models in a Preliminary Performance Assessment for the Waste Isolation Pilot Plant," Nuclear Engineering and Design 154, 251-344 (1995).

29. J.C. Helton et al., "Uncertainty and Sensitivity Analysis Resuits Obtained in the 1992 Performance Assessment for the Waste Isolation Pilot Plant," Reliability Engineering and System Safety 51, 53-100 (1996).

30. J.C. Helton and K.M. Trauth, "Comments on an Evaluation of the 1992 Performance Assessment for the Waste Isolation Pilot Plant," Núclear Engineering and Design 168, 339-360 (1997).

31. U.S. Environmental Protection Agency, "Environmental Radiation Protection Standards for the Management and Disposal of Spent Nuclear Fuel, High-Level and Transuranic Radioactive Wastes; Final Rule, 40 CFR Part 191, Federal Register 58, 66398-66416 (1993).

32. U.S. Environmental Protection Agency, "40 CFR Part 194: Criteria for the Certification and Re-Certification of the Waste Isolation Pilot Plant's Compliance With the 40 CFR Part 191 Disposal Regulations; Final Rule," Federal Register 61, 5224-5245 (1996).

33. U.S. Environmental Protection Agency, Compliance Application Guidance for 40 CFR Part 194. EPA 402-R95-014. (U.S. Environmental Protection Agency, Office of Radiation and Indoor Air, Washington, D.C., 1996).

34. J.C. Helton, "Computational Structure of a Performance Assessment Invoiving Stochastic and Subjective Uncertainty," I.M. Charnes, et al. (Eds.), Proceedings of the 1996 Winter Simulation Conference (Instutute of Electrical and Electronics Engineers, Piscataway, NJ, 1996), pp. $239-247$.

35. J.C. Helton, "Risk, Uncertainty in Risk, and the EPA Release Limits for Radioactive Waste Disposal," Nuclear Technology 101, 18-39 (1993).

36. J.C. Helton et al., "Performance Assessment for the Waste Isolation Pilot Plant: From Regulation to Calculation jor 40 CFR 191.13," Operations Research 45, 157-177 (1997).

37. I.C. Sanchez et al., "WIPP PA Analysis Report for EPAUNI: Estimating Probability Dismibution of EPA Unit Loading in the WIPP Repository for Performance Assessment Calculations," Version 1.01, Sandia WIPP Central Fles WPO

38. I.C. Helton et al., "Stochastic and Subjective Uncertainty in the Assessment of Radiation Exposure at the Waste Isolation Pilot Plant," Human and Ecological Risk Assessment 4, 469-526 (1998).

39. M.J. Stenhouse et al., SITE-94 Scenario Development FEP Audit List Preparation: Methodology and Presentation, SKI Technical Report 93:27 (Swedish Nuclear Power Inspectorate, Stockholm, 1993). 
40. J.C. Helton, "Treatment of Uncertainty in Performance Assessments for Complex Systems," Risk Analysis I4. 483-5.11 (1994).

41. J.C. Helton, "Uncertainty and Sensitivity Analysis in the Presence of Stochastic and Subjective Uncerainty." Journal of Statistical Computation and Simulation 57, 3-76 (1997).

42. W. Feller, An Introduction to Probabilin, Theor' and Its Applications, Volume II, Second Edition (John Wiley . \& Sons, New York, 1971).

43. K.M. Trauth et al., "Effectiveness of Passive Institutional Controls in Reducing Inadvertent Human Intrusion into the Waste Isolation Pilot Plant for Use in Performance Assessments," WIPP/CAO-96-3168. Revision 1, November 14, 1996 with Addendum of December 6, 1996 (U.S. Department of Energy, Carisbad Area Office, Carlsbad, NM, 1996).

44. J.C. Helton et al., Uncertainty and Sensitivity Analysis Results Obtained in the 1996 Pefformance Assessment for the Waste Isolation Pilot Plant, SAND98-0365 (Sandia National Laboratories, Albuquerque, NM, 1998).

45. D.W. Powers et al., "Probability of Intercepting a Pressurized Brine Reservoir under the WIPP," Sandia WIPP Central Files WPO

46. T.W. Thompson et al., "Inadvertent Intusion Borehole Permeability, Final Draft," May 20, 1996, Sandia WIPP

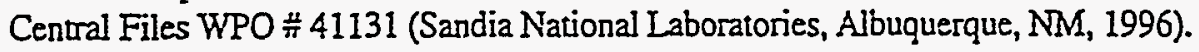

47. J.E. Bean et al., "Analysis Package for the Salado Flow Calculations (Task 1) of the Performance Assessment Analysis Supporting the Compliance Certification Application (CCA)," Analysis package, SWCFA:1.2.07.4.1:PA:QA:CCA, Sandia WIPP Central Files WPO $\frac{\| t}{\pi} 40514$ (Sandia National Laboratories, Albuquerque, NM, 1996).

48. D.M. Stoelzel and D.G. O'Brien, "Analysis Package for the BRAGFLO Direct Release Calculations (Task 4) of the Performance Assessment Calculations Supporing the Compliance Certification Application (CCA), AP-029, Brine Release Calculations," Anälysis package, SWCF-A:1.2.07.4.1:PA:QA, Sandia WIPP Central Files WPO

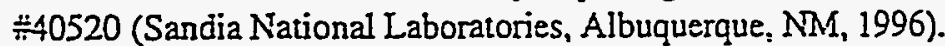

49. C. Wilson, D. Porter, J. Gibbons, R. Oswald and G. Sjoblom, Waste Isolation Pilot Plant Conceptual Models Peer Review: Final Report, DOE/CAO-1996-1995 (U.S. Deparment of Energy, Waste Isolation Pilot Plant, Carisbad Area Office, Carisbad, NM, 1997).

50. J.W. Berglund, Mechanisms Governing the Direct Removal of Wastes from the Waste Isolation Pilot Plant Repository' Caused by' Exploratory Driliing, SAND92-7295 (Sandia National Laboratories, Albuquerque, NM. 1992).

51. Berglund, J.W. "Analysis Package for the Cuttings and Spalling Calculations (Tasks 5 and 6) of the Performance Assessment Caiculation Supporing the Compliance Certification Application (CCA), AP-015 and AP-016," Analysis package, SWCF-A:1.2.07.4.1:PA:CCA:QA, Sandia Central Files WPO $\frac{\mu}{\pi} 40521$ (Sandia National Laboratories, Albuquerque, NM, 1996).

52. A.M. LaVenue and B.S. RamaRao, A Modeling Approach To Address Spatial Variability Within the Culebro Dolomite Transmissivity Field, SAND92-7306 (Sandia National Laboratories, Albuquerque, NM, 1992).

53. A.M. LaVenue, "Analysis of the Generation of Transmissivity Fields for the Culebra Dolomite Compliance Certification Application (CCA)," Analysis package, SWCF-A:1.2.07.4.1:PA:QA, Sandia WIPP Central Files WPO \#40517 (Sandia National Laboratories, Albuquerque, NM, 1996). 
54. C. Stockman et al.. "Analysis Package for the Salado Transpor Calculations (Task 2) of the Performance Assessment Analysis Supporting the Compliance Cerification Application (CCA), AP-023," Analysis package, SWCF-A:1.2.07.4.1:PA:QA:CCA, Sandia WIPP Central Files WPO \#40515 (Sandia National Laboratories, Albuquerque. NM, 1996).

55. C.M. Stone, SÁNTOS - A Two-Dimensional Finite Element Program for the Quasistatic, Large Deformation, Inelestic Response of Solids, SAND90-0543 (Sandia National Laboratories, Albuquerque, NM, 1997).

56. C.M. Stone, Final Disposal Room Structural Response Calculations, SAND97-0795 (Sandia National Laboratories, Albuquerque, NM, 1997).

57. P.J. Roache, "The SECO Suite of Codes for Site Performance Assessment," in High Level Radioacrive Wasle Management, Proceedings of the Fourth Annual International Conference, Las Vegas, NV, April 26-30, 1993, Vol. 2. (American Nuclear Society, La Grange Park, II, 1993) pp. 1586-1594.

58. J. Ramsey and M.G. Wallace, "Analysis Package for the Culebra Flow and Transport Calculations (Task 3) of the Performance Assessment Calculations Supporting the Compliance Certification Application (CCA), Analysis Plan 019," Analysis package, SWCF-A:WA:1.2.07.4.1:QA, Sandia WIPP Central Files WPO "40516 (Sandia National Laboratories, Albuquerque, NM, 1996).

59. J.C. Heiton and A.W. Shiver, "A Monte Carlo Procedure for the Construction of Complementary Cumulative Distribution Functions for Comparison with the EPA Release Limits for Radioactive Waste Disposal," Risk Analysis 16, 43-55 (1996).

60. L.N. Smith et al., "Analysis Package for the CCDF Construction (Task 7) of the Performance Assessment Calculations Supporting the Compliance Certification Application (CCA), AP-AAD," Analysis package, SWCFA:1.2.07.4.1:PA:QA, Sandia WIPP Central Files WPO \# 40524 (Sandia National Laboratories, Albuquerque, NM, 1996).

61. J.D. Johnson, "CCDFGF, Version 4.00, User's Manual," Sandia WIPP Central Files WPO \# 47364 (Sandia National Laboratories, Albuquerque, NM, 1097).

62. McKay, M.D. et al., "A Comparison of Three Methods for Selecting Values of Input Variables in the Analysis of Output from a Computer Code," Technometrics 21, 239-245 (1979).

63. Iman, R.L. and W.J. Conover. "A Disuibution-Free Approach to Inducing Rank Correlation Among Input Variables," Communications in Statistics: Simulation and Computation B11, $311-334$ (1982).

64. Iman, R.L. and I.M. Davenport. "Rank Correlation Plots for Use with Correlated Input Variables," Communications in Statistics: Simulation and Computation B11, 335-360 (1982).

65. R. MacKinnon et al., "Summary of EPA-Mandated Perfornance Assessment Verification Test (Replicate 1) and Comparison with the Compliance Certification Application Calculations," Technical Data Package, Sandia WTPP. Central Files WPO $\stackrel{*}{\longleftarrow} 46674$ (Sandia National Laboratories, Albuquerque, NM, 1997).

66. J.C. Helton, "Probability, Conditional Probability and Complementary Cumulative Distribution Functions in Performance Assessment for Radioactive Waste Disposal," Reliability Engineering and System Safery 54, 145163 (1996).

67. R.I. Iman and J.C. Helton, "An Investigation of Uncertainty and Sensitivity Analysis Techniques for Computer Models," Risk Analysis 8, 71-90 (1988).

68. R.I. Iman and J.C. Helton, "The Repeatability of Uncertainty and Sensitivity Analyses for Complex Probabilistic Risk Assessments," Risk Analysis 11, 591-606 (1991). 
69. J.C. Helton et al., "Robustness of an Uncerainty and Sensitivity Analysis of Early Exposure Results with the MACCS Reactor Accident Consequence Model," Reliability Engincering and Systcm Safay 48, 129-148 (1995).

70. R.L. Iman, "Statistical Methods for Including Uncertainties Associated with Geologic Isolation of Radioactive Waste Which Allow for a Comparison with Licensing Criteria," in D.C. Kocher (ed.), Proceedings of the Symposium on Uncenainties Associated with the Regulation of the Geologic Disposal of High-Level. Radioactive Waste: March 9-13, 1981, Gatlinburg, TN, NUREG/CP-0022, CONF-810372 (Oak Ridge National Laboratory, Oak Ridge, TN, 1982) pp. 145-157.

71. U.S. Department of Energy, Transuranic Waste Baseline Inventory Report (Revision 3), DOE/CAO-95-1121 (U.S. Deparment of Energy, Carlsbad Area Office, Carisbad, NM, 1996).

72. F.R. Farmer, "Reactor Safety and Siting: A Proposed Risk Criterion," Nuclear Safery 8, 539-548 (1967).

73. D.C. Cox and P. Baybutt, "Limit Lines for Risk," Nuclear Technology 57, 320-330 (1982).

74. H.A. Munera and G. Yadigaroglu, "On Farmer's Line, Probability Density Functions, and Overall Risk," Nuclear Technology 74, 229-232 (1986).

75. J.C. Helton and R.J. Breeding, "Calculation of Reactor Accident Safety Goals," Reliabiliti Engineering and System Safety' 39, 129-158 (1993).

76. U.S. Nuclear Regulatory Commission, "Safety Goals for the Operation of Nuclear Power Plants: Policy" Statement. Correction and Republication," Federal Register 51, 30028-30033 (1986).

77. S. Kaplan and B.J. Garrick, "On the Quantitative Definition of Risk," Risk Analysis 1, 11-27 (1981).

78. F.O. Hoffman and J. S. Hammonds, "Propagation of Uncertainty in Risk Assessments: The Need to Distinguish Between Uncertainty Due to Lack of Knowledge and Uncertainty Due to Variability," Risk Analysis 14, 707712 (1994).

79. J.C. Helton and D.E. Burmaster, "Guest Editorial: Treatment of Aleatory and Epistemic Uncertainty in Performance Assessments for Complex Systems," Reliability Engineering and System Safetj 54, 91 -94 (1996).

80. M.E. Paté-Comell, "Uncertainties in Risk Analysis: Six Levels of Treatment," Reliability' Engineering and Sysțem Safety 54, 95-111 (1996).

81. K.M. Thompson and J.D. Graham, "Going Beyond the Single Number: Using Probabilistic Risk Assessment to Improve Risk Management," Human and Ecological Risk Assessment 2, 1008-1034 (1996).

82. U.S. Deparment of Energy, Quality Assurance Program Document, CAO-94-1012, Rev. 1 (U.S. Deparment of Energy, Carlsbad Area Office, Carlsbad, NM, 1996).

83. J.C. Helton et al., Sensitivity Analysis Techniques and Results for Performance Assessment at the Weste Isolation Pilot Plant, SAND90-7103 (Sandia National Laboratories, Albuquerque, NM, 1991).

84. J.C. Helton et al., Uncertainty and Sensitivity Analyses for Gas and Brine Migration at the Waste Isolation Pilot Plont, May 1992, SAND92-2013 (Sandia National Laboratories, Albuquerque, NM, 1993).

85. J.C. Helton, "Uncertainty and Sensitivity Analysis Techniques for Use in Performance Assessment for Radioactive Waste Disposal," Reliability Engineering and System Safety 42, 327-367 (1993). 
S6. U.S. Environmental Protection Agency: "Criteria for the Certification and Re-Certification of the Wastc Isolation Pilot Plant's Compliance With the 40 CFR Part 191 Disposal Regulations: Preliminary Certinication Decision." Fcderal Register 62.58791-58838 (1997). 
Figure Captions

Fig. 1. Cross-sectional view of the WIPP (Fig. 1-9, Vol. 1, Ref. 3; see Sect. 2.2, Vol. 2. Ref. 4, for detailed stratigraphy).

Fig. 2. Boundary line and associated CCDF specified in 40 CFR 191, Subpart B (Fig. 4. Ref. 38); see Sects. 4 and 5 for a discussion of this CCDF as an integral involving a probability space $\left(\delta_{s l}, \delta_{s s}, p_{s s}\right)$ for stochastic. uncertainty and a function $f$ defined on $\delta_{s t^{*}}$.

Fig. 3. Computer programs (models) used in 1996 WIPP PA (Fig. 5, Ref. 38).

Fig. 4. Example of an uncerain variable, its associated distribution, and sampled values obtained with a Latin hybercube sample ${ }^{62}$ of size 100 (see App. PAR, Ref. 5 , for distributions of the $n V=57$ variables in $x_{s u}$ ).

Fig. 5. Scatterplot illustrating correlation within the pair (BPCOMP, BPPRM); see Fig. 5.4.1, Ref. 44, for correlations within the pairs (ANHCOMP, ANHPRM) and (HALCOMP, HALPRM).

Fig. 6. Distribution of CCDFs resulting from possible values for $x_{s u} \in S_{s u}$ (adapted from Fig. 2, Ref. 41).

Fig. 7. Distribution of exceedance probabilities due to subjective uncerainty (adapted from Fig. 3, Ref. 41).

Fig. 8. Example CCDF distribution from 1992 WIPP PA (Fig. 10, Ref. 37).

Fig. 9. Distribution over all 300 LHS elements for original (i.e., uncompacted) volume removed due to cuttings and cavings by a single drilling intrusion through $\mathrm{CH}-\mathrm{TRU}$ waste.

Fig. 10. Average concentration (EPA units $/ \mathrm{m}^{3}$ ) of $\mathrm{CH}$ - and RH-TRU waste.

Fig. 11. Distribution of normalized release to accessible environment for cuttings removal from CH-TRU waste due to variation in intersected waste streams. Results calculated with median volume from Fig. 9 (i.e., $\left.0.508 \mathrm{~m}^{3}\right), 38.6 \%$ of removed volume assumed to be $\mathrm{CH}$-TRU waste, and a sample of size 10,000 at each time.

Fig. 12. Repository pressure for 100 tHS elements in replicate R1: (12a) undisturbed (i.e., E0) conditions, and (12b) E1 intrusion at $1000 \mathrm{yr}$.

Fig. 13. Distribution over all 300 LHS elements for original (i.e., uncompacted) volume removed $\left(\mathrm{m}^{3}\right)$ and normalized release (EPA units) due to spallings for a single drilling intrusion into a previously unintruded repository that encounters $\mathrm{CH}-\mathrm{TRU}$ waste.

Fig. 14. Distribution over all 300 LHS elements for original (i.e., uncompacted) volume removed $\left(\mathrm{m}^{3}\right)$ and normalized release (EPA units) due to spallings for the second drilling intrusion into CH-TRU waste after an initial El intrusion at $1000 \mathrm{yr}$.

Fig. 15. Distribution over all 300 LHS elements for brine release $\left(\mathrm{m}^{3}\right)$ and normalized release (EPA units) due to direct brine release for a single drilling intrusion into a previously unintruded repository.

Fig. 16. Radionuclide concentration (EPA units $/ \mathrm{m}^{3}$ ) in repository with $\mathrm{MgO}$ backfill.

Fig. 17. Cumulative brine flow up borehole at top of DRZ for 100 LHS elements in Replicate R1: (17a) El intrusion, (17b) E2 intrusion, and (17c) E2E1 intrusion. 
Fig. IS. Curnulative radionuclide transpor over 10.000 from repository to Culebra Dolomite for El intrusions: (18a) individual radionuclides with an $E l$ intrusion at 1000 yr, and (18b) total release for $E l$ intrusions at $100,350,1000,3000,5000,7000$ and $9000 \mathrm{yr}$.

Fig. 19. Cumulative normalized release from repository to Culebra Dolomite for an El intrusion at $1000 \mathrm{yr}$.

Fig. 20. Distributions of CCDFs for normalized release to the accessible environment over $10.000 \mathrm{yr}$ for replicate $\mathrm{Rl}$ : (20a) cuttings and cavings, (20b) spallings, (20c) direct brine release, and (20d) total release (Figs. 6. 9, Ref. 38).

Fig. 21. Mean and percentile curves for total normalized release (i.e., cuttings, cavings, spallings and direct brine) to the accessible environment over 10,000 yr obtained by pooling results for replicates RI, R2 and R3.

Fig. 22. Outcome of replicated sampling for distribution of CCDFs for total normalized release to the accessible environment over 10,000 yr: (22a) mean and percentile curves for individual replicates, and (22b) confidence intervals (CIs) on mean curve obtained from the three replicates (Fig. 8, Ref. 38). 



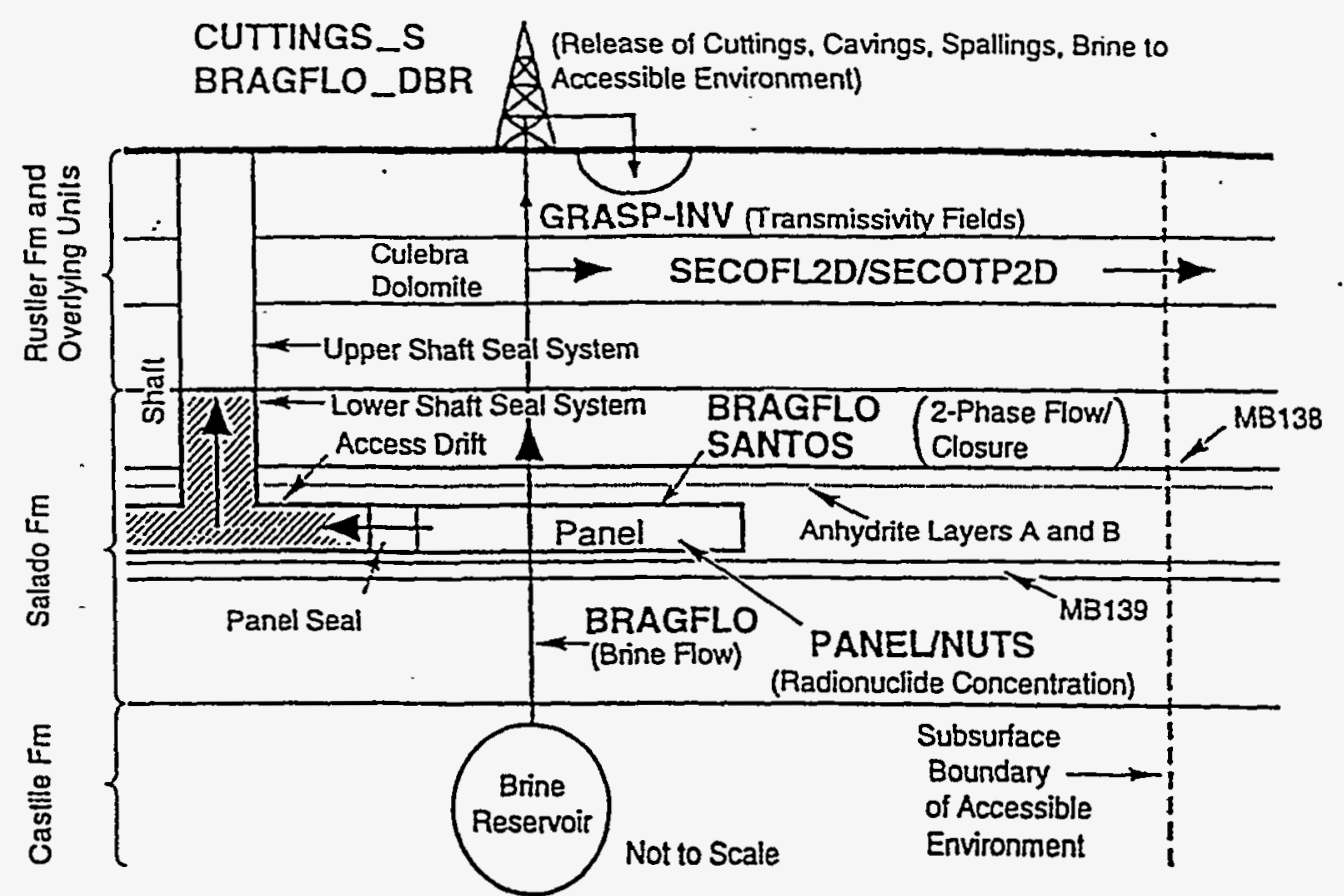

TH1-6342-3409-19

Fig. 3. Computer programs (models) used in 1996 WIPP PA (Fig. 5, Ref. 38).

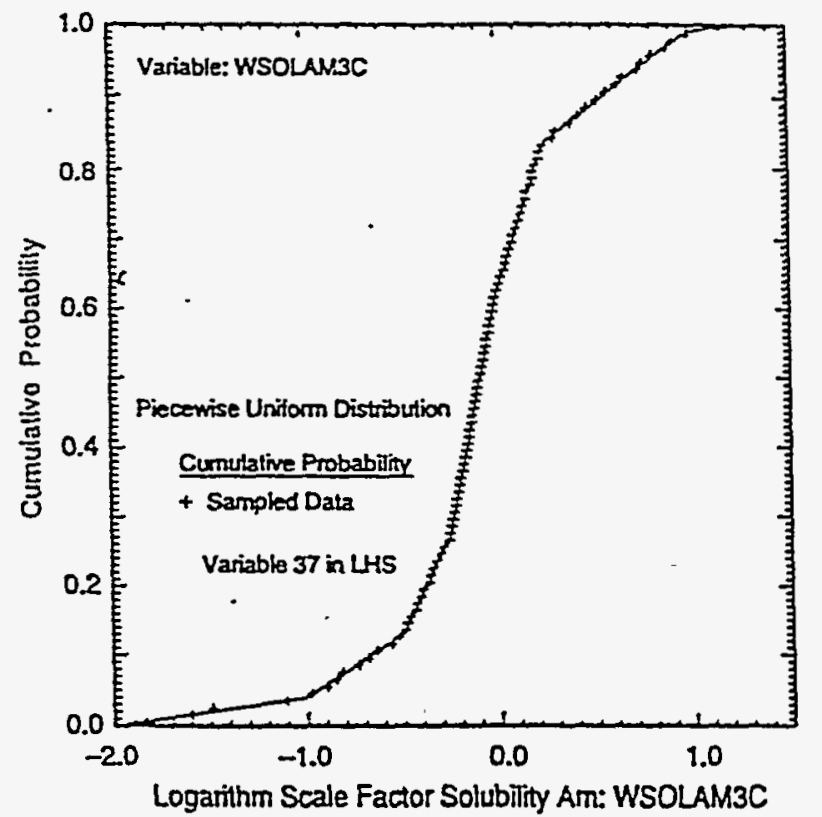

TR1-0312-5173-S

Fig. 4. Example of an uncertain variable, its associated distribution, and sampled values obtained with a Latin hybercube sample ${ }^{62}$ of size 100 (see App. PAR, Ref. 5, for distributions of the $n V=57$ variables in $x_{s u}$ ). 


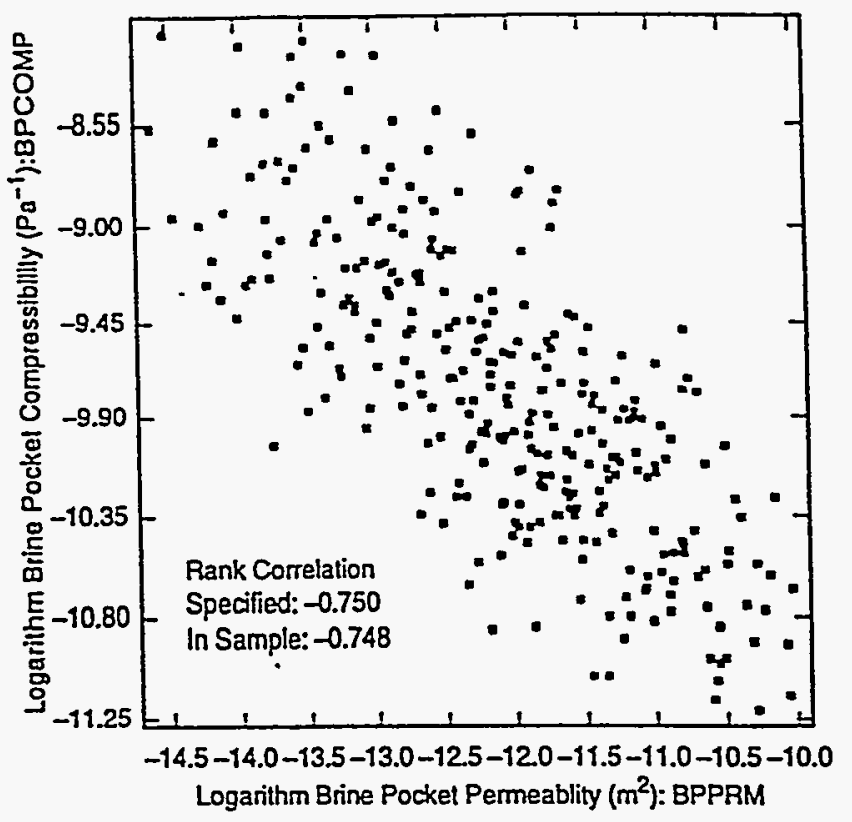

TRI-6342-5174-Odup

Fig. 5. Scatterplot illustrating correlation within the pair (BPCOMP, BPPRM); see Fig. 5.4.1, Ref. 44, for correlations within the pairs (ANHCOMP, ANHPRM) and (HALCOMP, HALPRM).

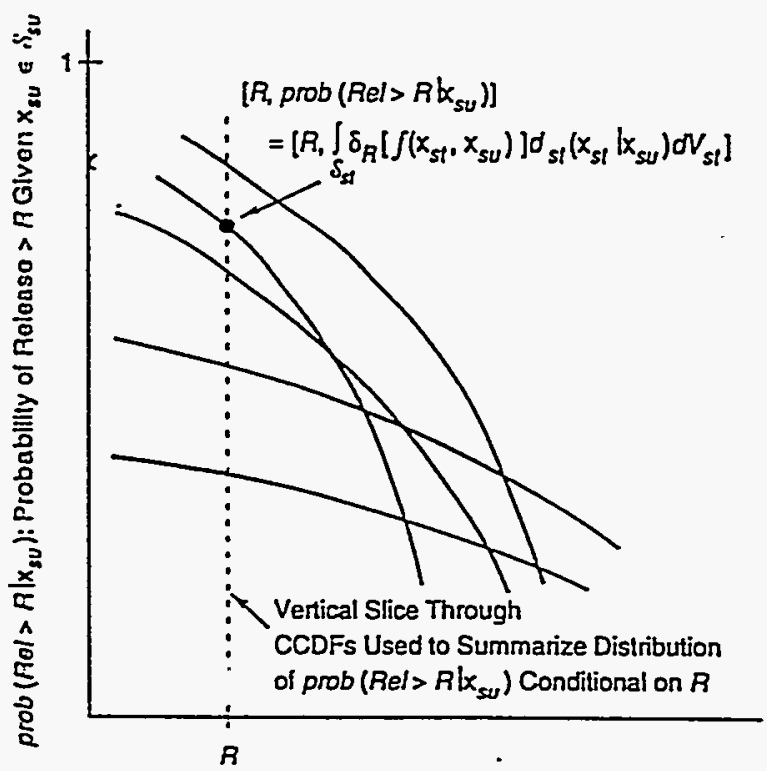

R: Release to Accessible Environment $\left[=f\left(x_{s t}, x_{s u}\right)\right]$

TRI-6342-1639-3

Fig. 6. Distribution of CCDFs resuling from possible values for $x_{s u} \in \mathcal{S}_{s u}$ (adapted from Fig. 2, Ref. 41). 


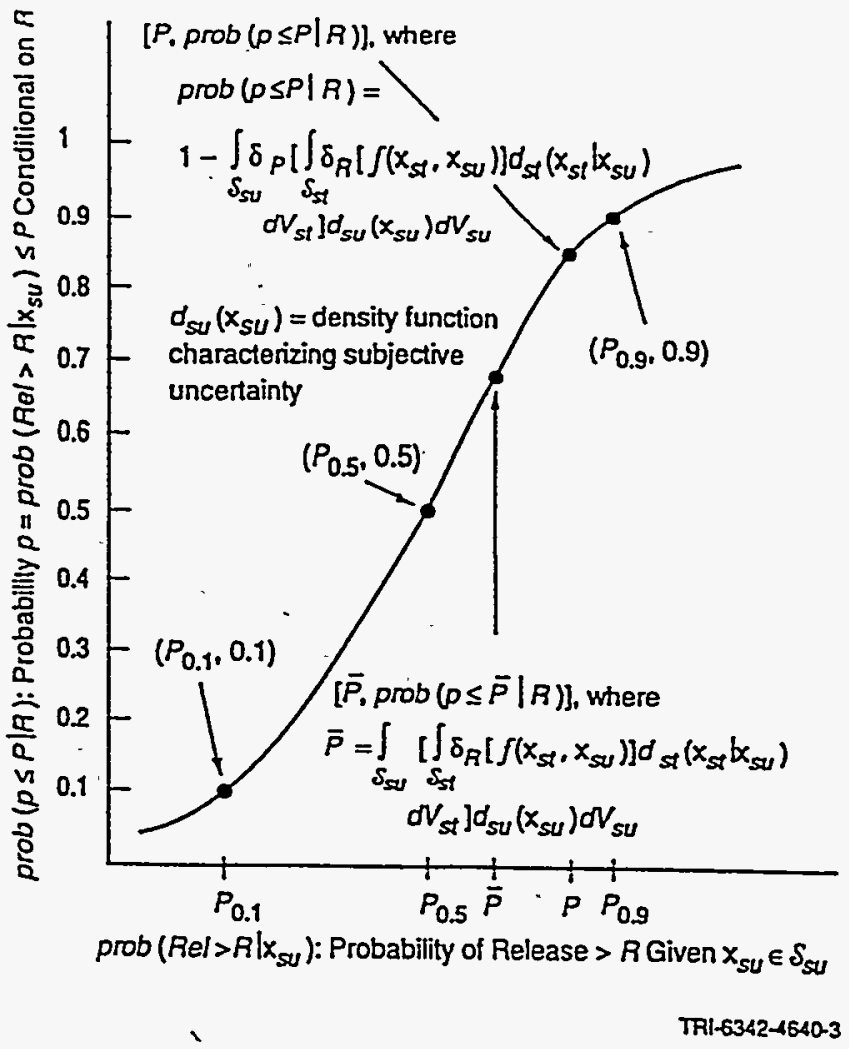

Fig. 7. Distribution of exceedance probabilities due to subjective uncertainty (adapted from Fig. 3, Ref. 41).
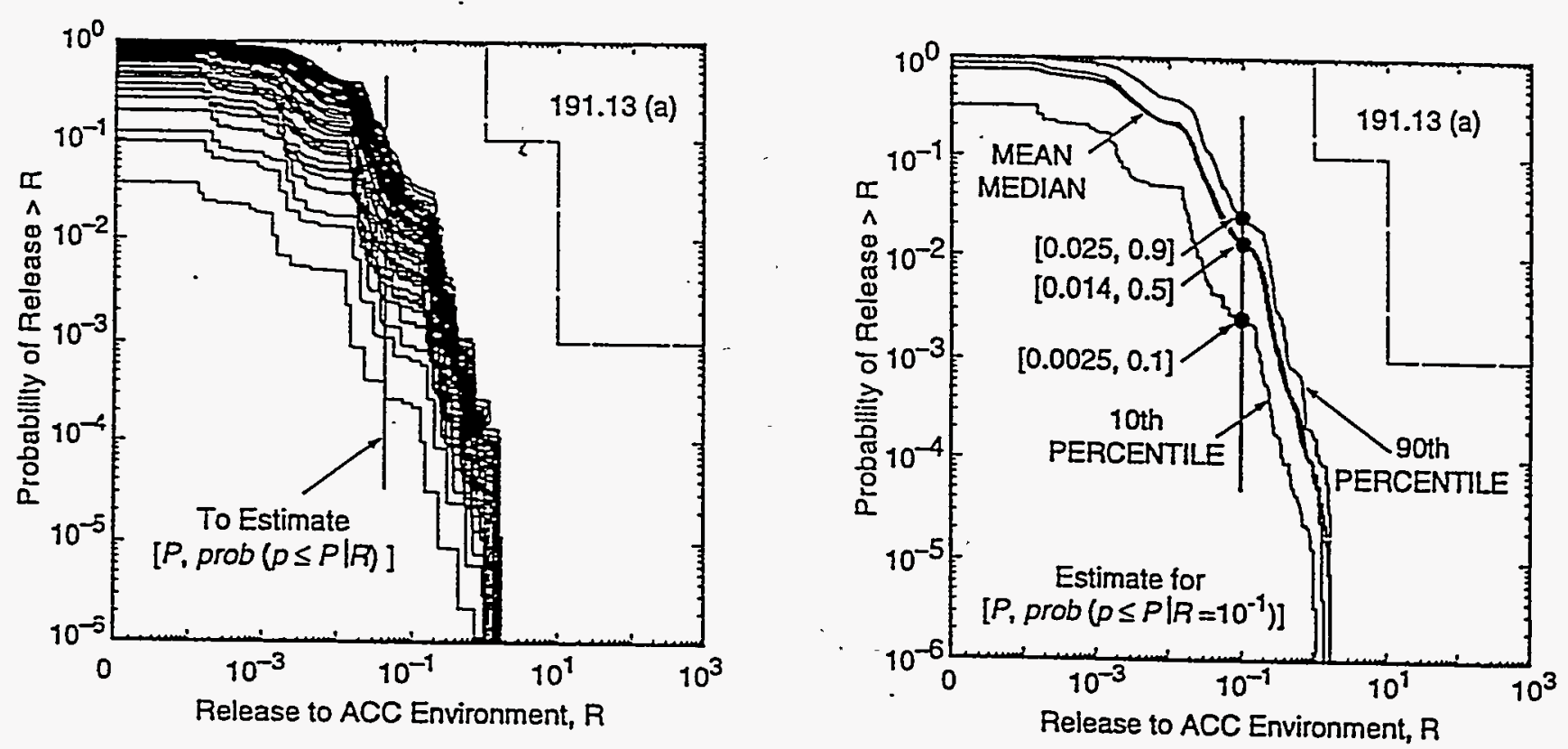

$\operatorname{TRI}-6342-6007-0$

Fig. 8. Example CCDF distribution from 1992 WIPP PA (Fig. 10, Ref. 37). 


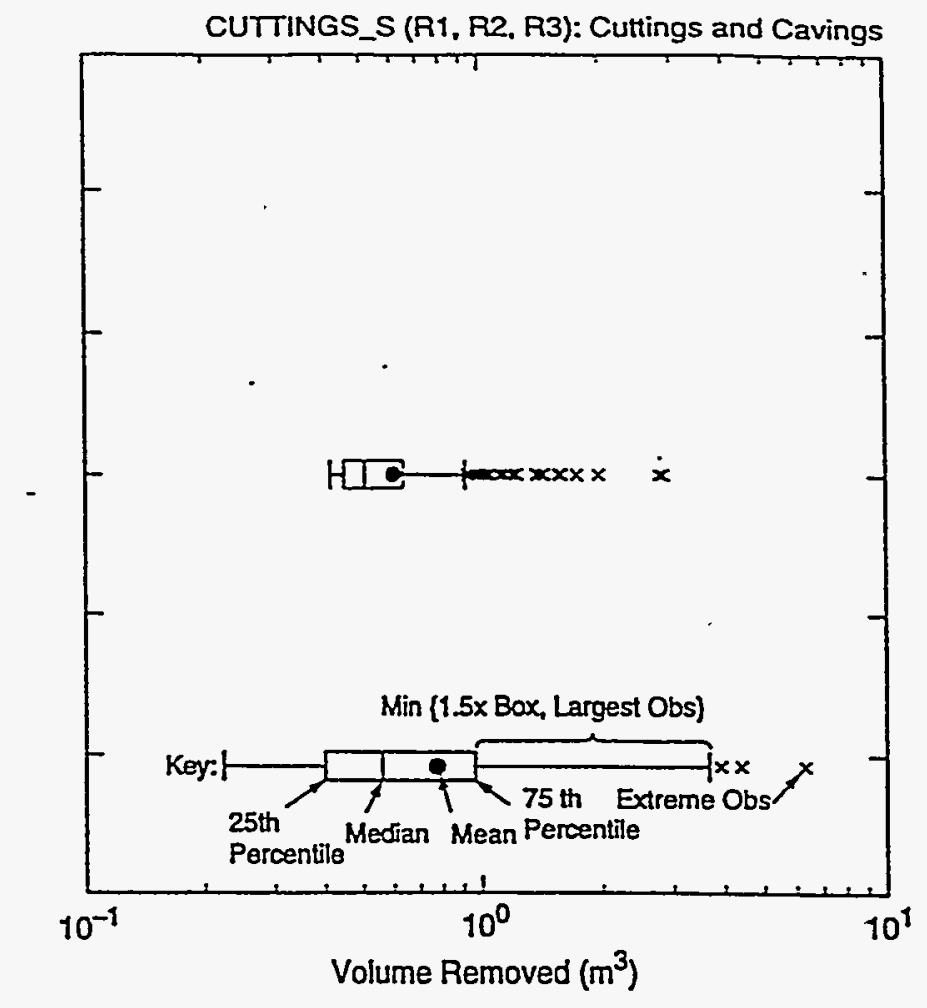

TRI-5342-4785-1

Fig. 9. Distribution over all 300 LHS elements for original (i.e., uncompacted) volume removed due to cuttings and cavings by a single drilling intrusion through $\mathrm{CH}$-TRU waste.

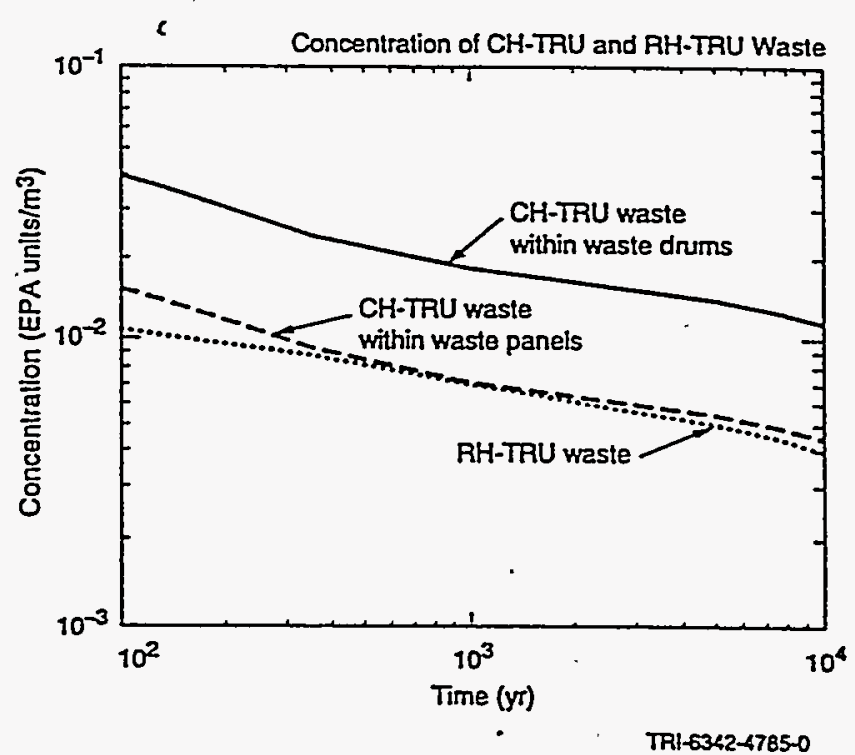

Fig. 10. Average concentration (EPA units/m ${ }^{3}$ ) of $\mathrm{CH}$ - and RH-TRU waste. 


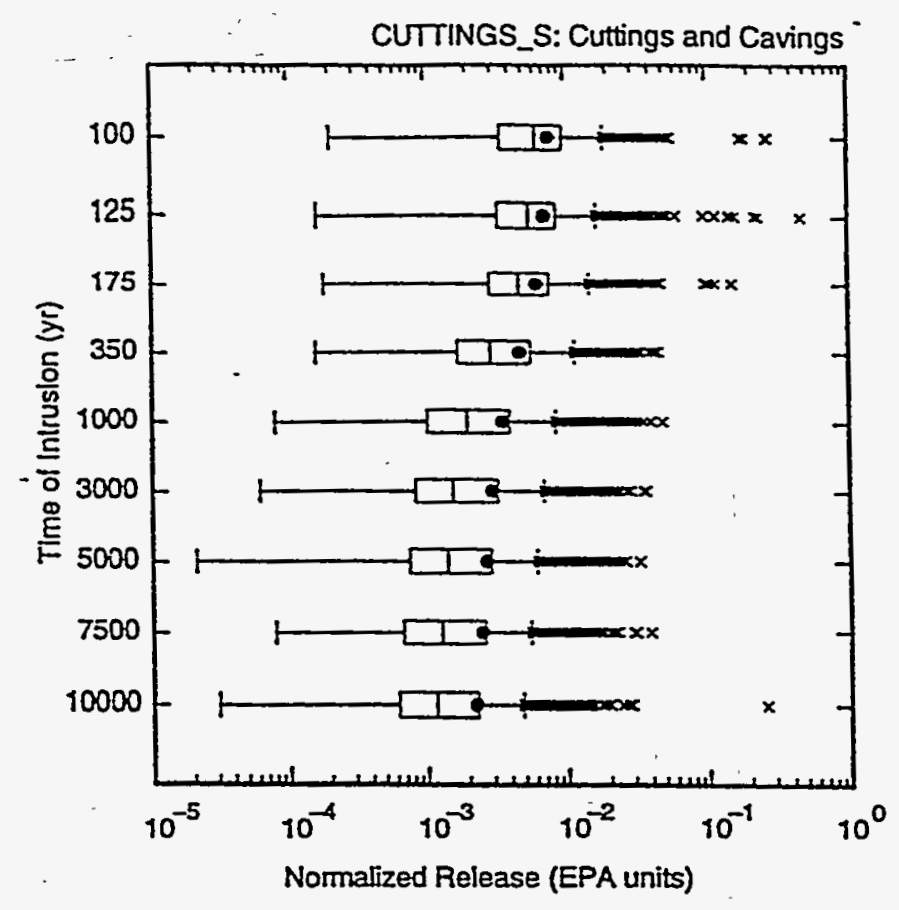

TR1-6342-4788-1

Fig. 11. Distribution of normalized release to accessible environment for cuttings removal from $\mathrm{CH}$-TRU waste due to variation in intersected waste streams. Results calculated with median volume from Fig. 9 (i.e., $0.508 \mathrm{~m}^{3}$ ), $38.6 \%$ of removed volume assumed to be $\mathrm{CH}$-TRU waste, and a sample of size 10.000 at each time.
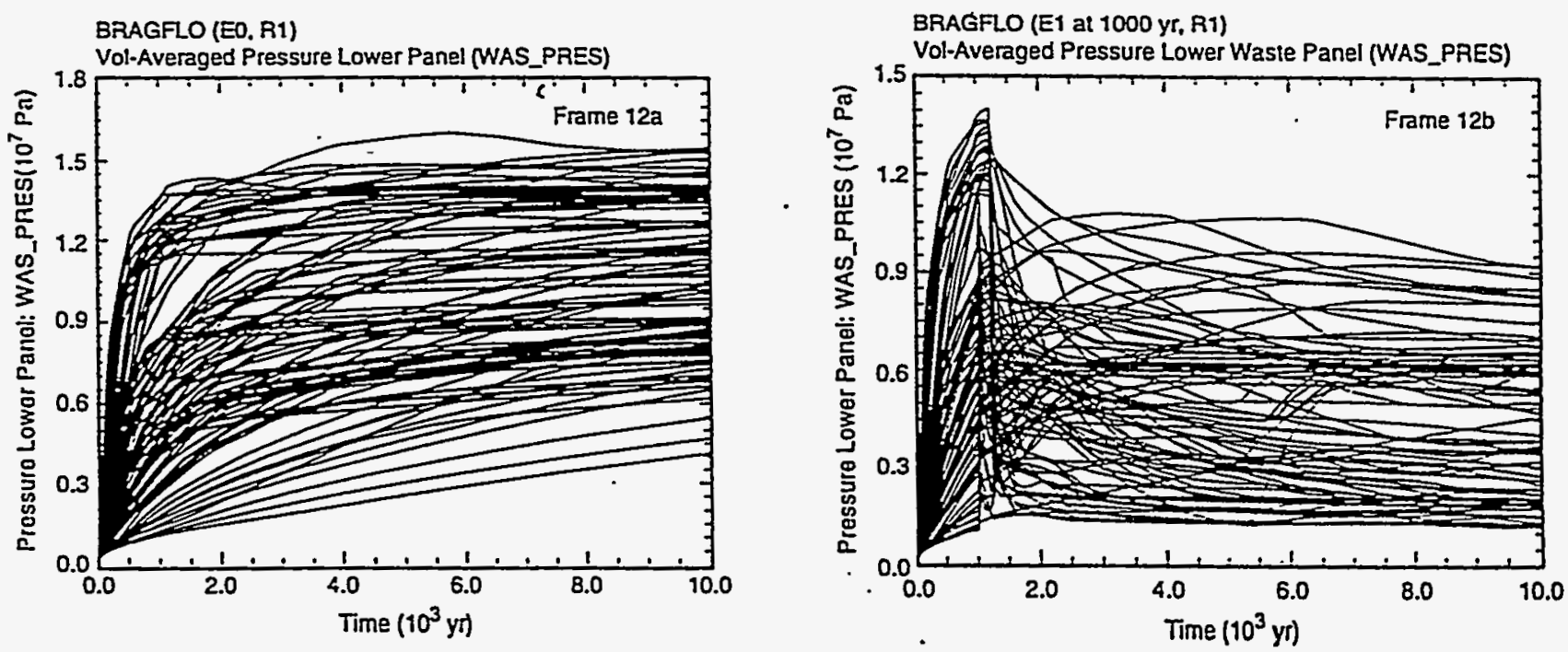

TRI.6342.5721-0

Fig. 12. Repository pressure for 100 LHS elements in replicate Rl: (12a) undisturbed (i.e., E0) conditions, and (12b) an $\mathrm{El}$ intrusion at $1000 \mathrm{yr}$. 

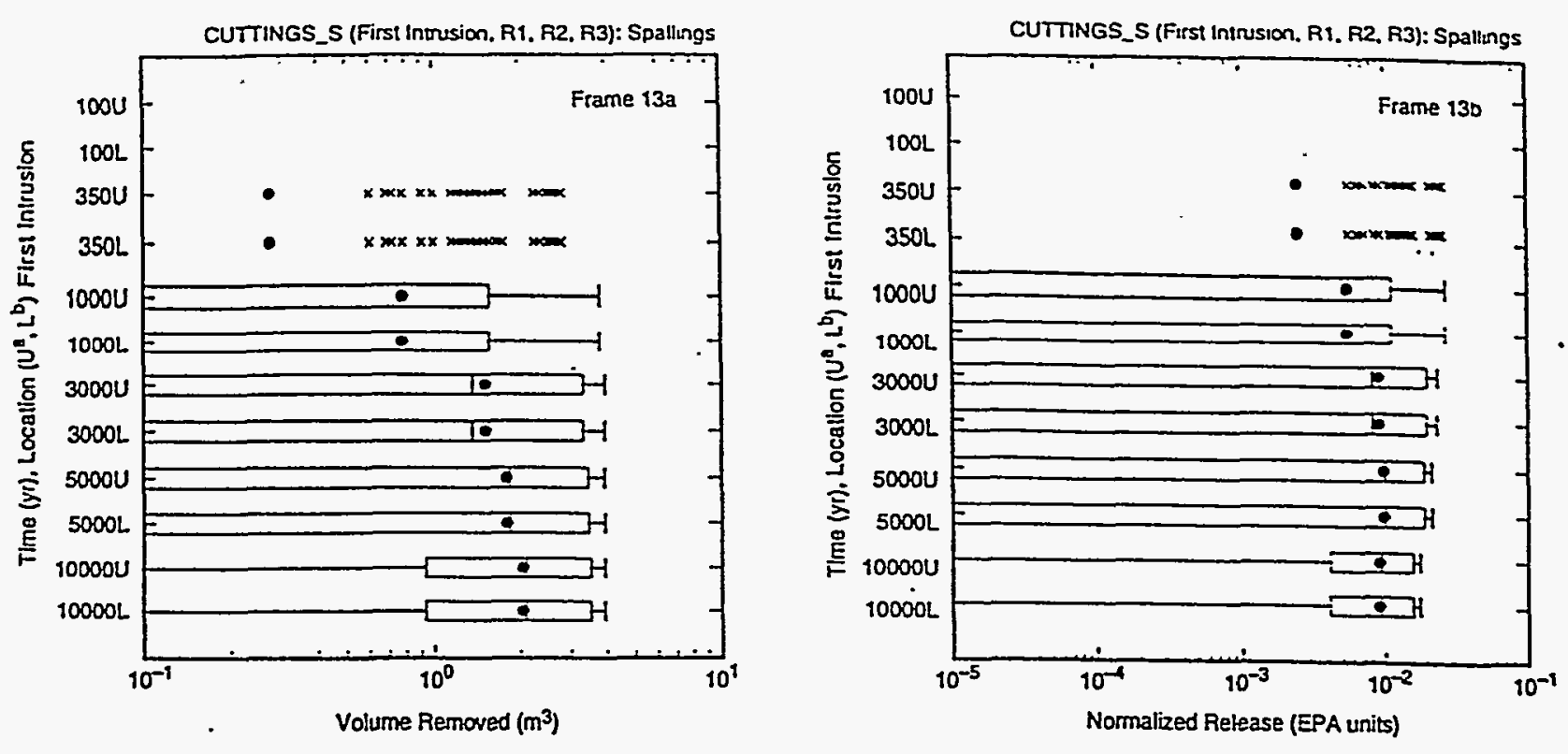

aU Signifies Intrusion into an Upper (U) Waste Panel $b_{L}$ Signifies Intrusion into an Lower (L) Waste Panel

$\pi n 1-53+2<\pi 73-3$

Fig. 13. Distribution over all 300 LHS elements for original (i.e., uncompacted) volume removed $\left(\mathrm{m}^{3}\right.$ ) and normalized release (EPA units) due to spallings for a single drilling intrusion into a previously unintruded repository that encounters $\mathrm{CH}$-TRU waste.
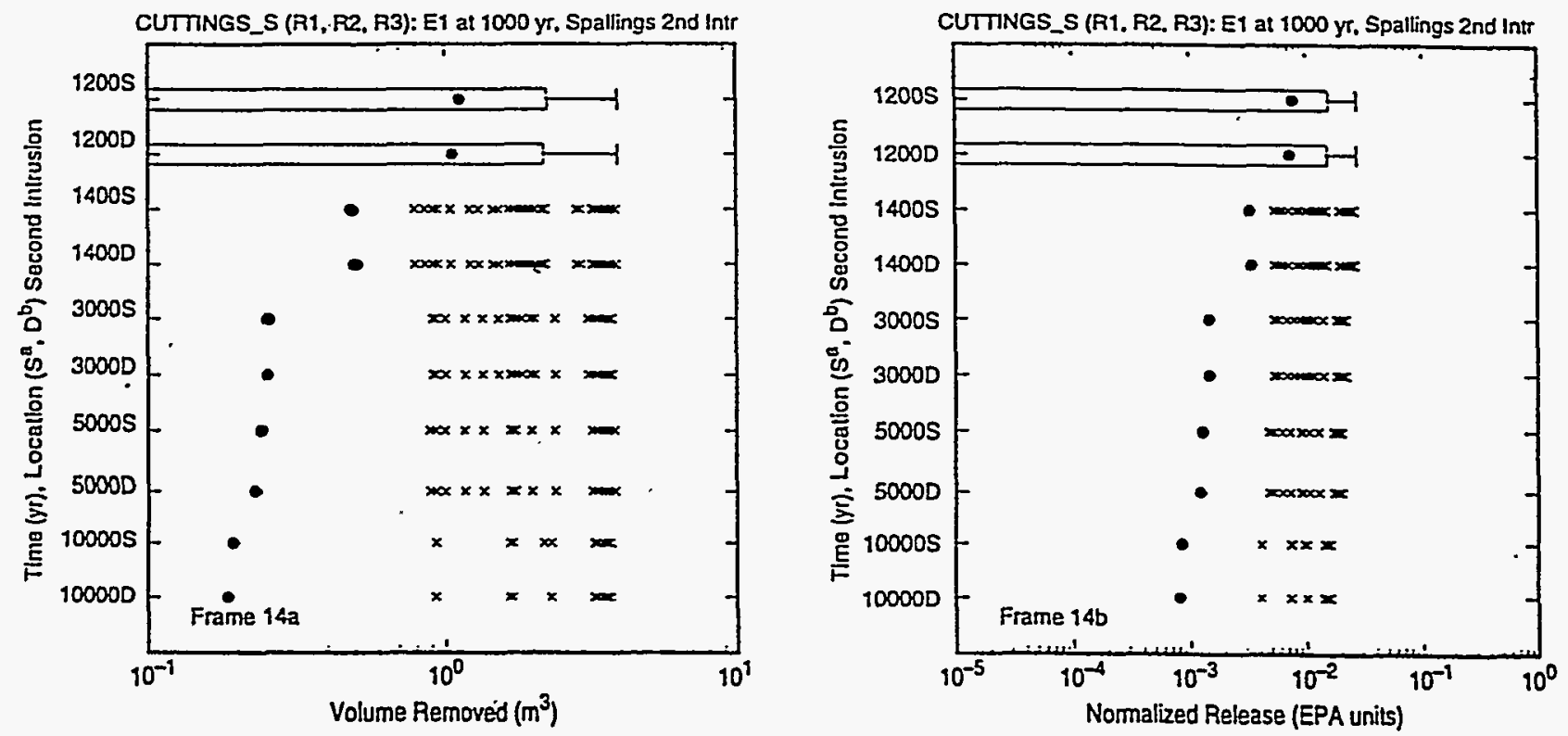

as Signifies Second Intrusion Ocaurs in Same (S) Waste Panel as First Intrusion

Do Signifies Second Intrusion Oceurs in Different (D) Waste Panel than First Intrusion

TR1-63+2-4782-2

Fig. 14. Distribution over all 300 LHS elements for original (i.e., uncompacted) volume removed $\left(\mathrm{m}^{3}\right.$ ) and normalized release (EPA units) due to spallings for the second drilling intrusion into $\mathrm{CH}$-TRU waste after an initial $E l$ intrusion at $1000 \mathrm{yr}$. 

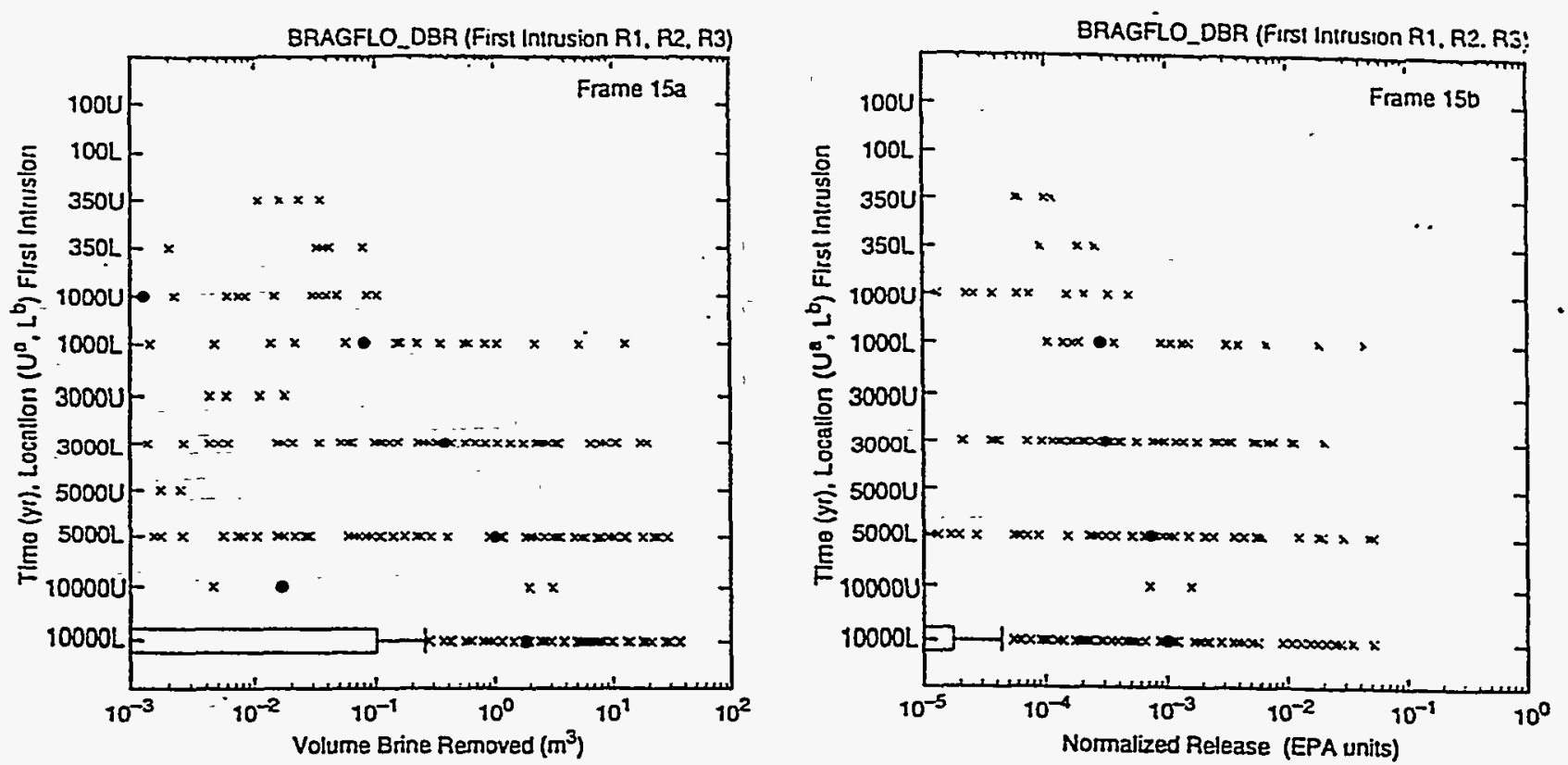

${ }^{2} U$ Signifies Intrusion into an Upper (U) Waste Panel

b Signifies Intrusion into a Lower (L) Waste Panel

TRI- $6342-475-2$

Fig. 15. Distribution over all 300 LHS elements for brine release $\left(\mathrm{m}^{3}\right)$ and normalized release (EPA units) due to direct brine release for a single drilling intrusion into a previously unintruded repository.
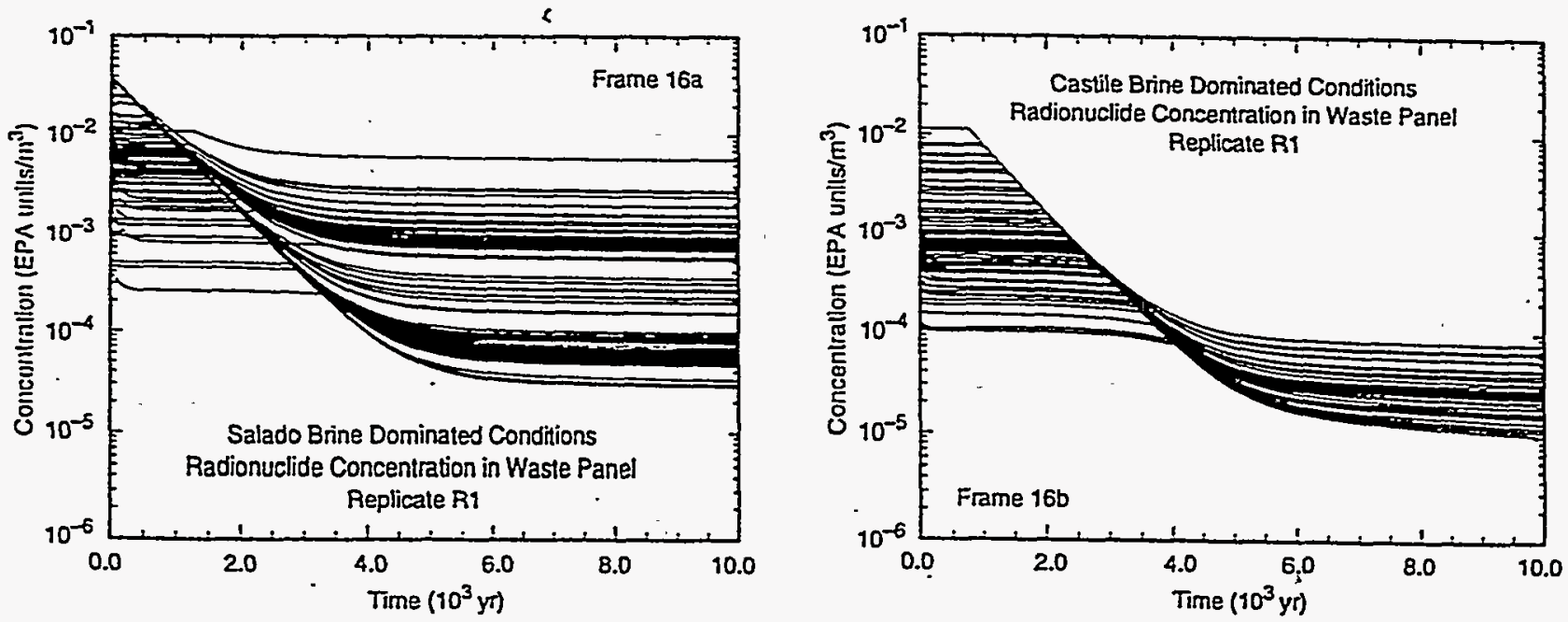

TRI-63<2 $<777-2$

Fig. 16. Radionuclicie concentration (EPA units $/ \mathrm{m}^{3}$ ) in repository with $\mathrm{MgO}$ backfill. 
BRAGFLO (E1 at $1000 \mathrm{yr}$. R1)

Cum Bnne Flow Oul Upper DRZ at Borehole (BNBHUDRZ)
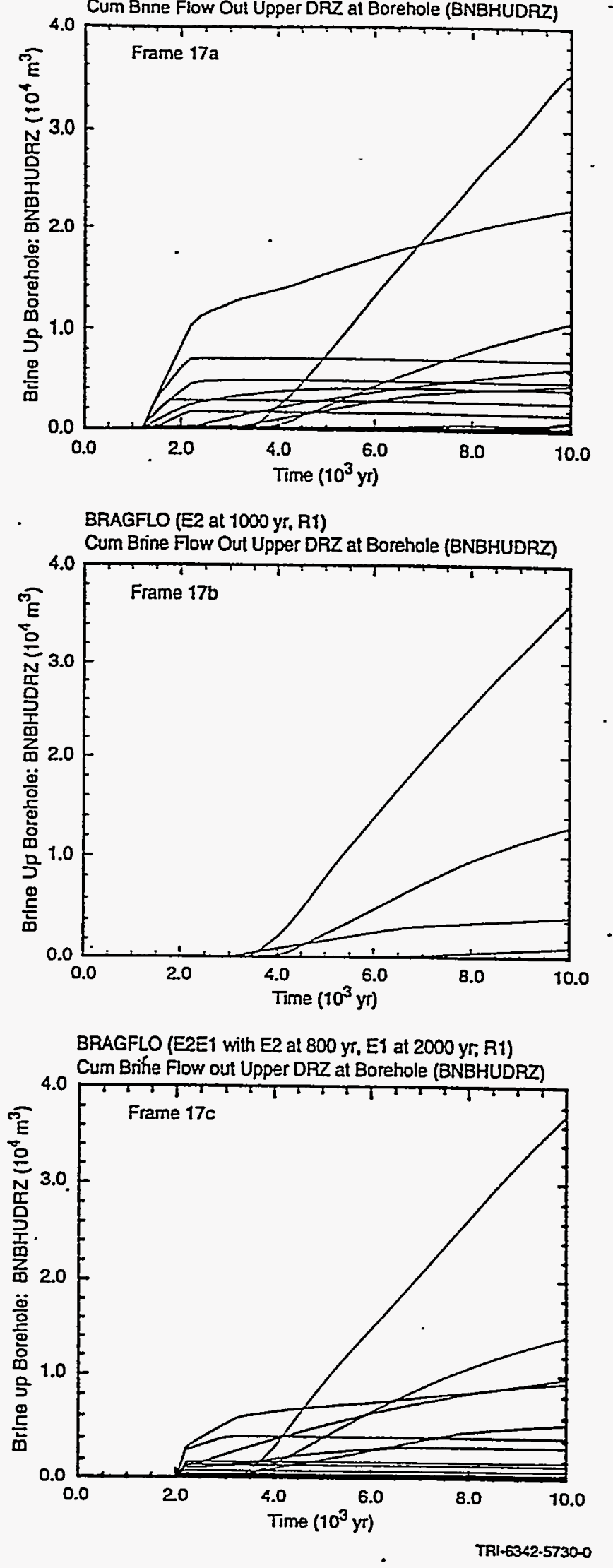

Fig. 17. Cumulative brine flow up borehole at top of DRZ for 100 LHS elements in Replicate R1: (17a) El intrusion, (17b) E2 intrusion, and (17c) E2E1 intrusion. 
NUTS (E1 at 1000 yr, R1. R2. R3)

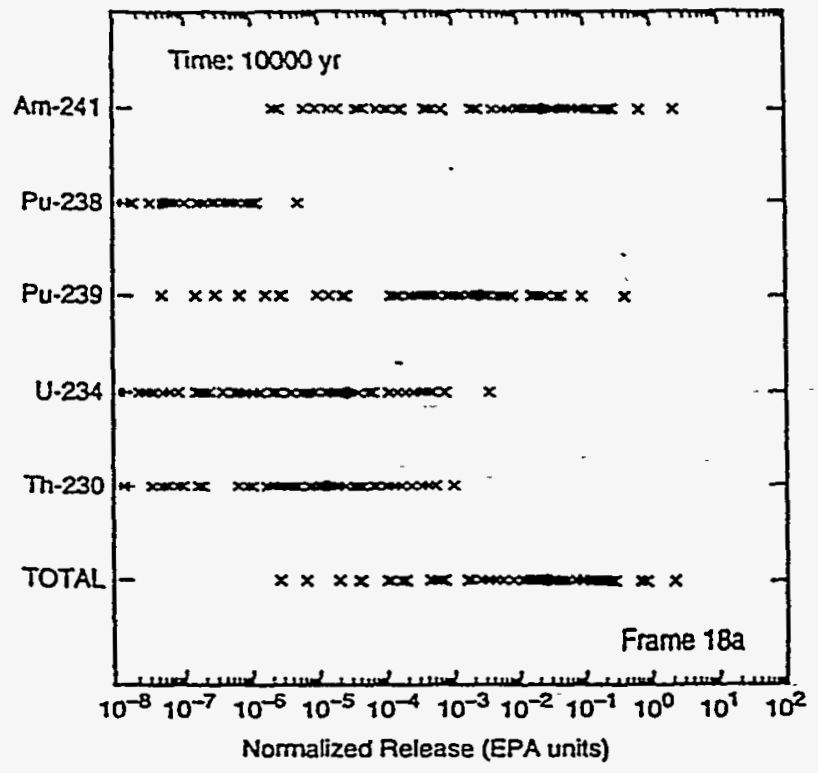

NUTS (E1, R1, F2, R3)

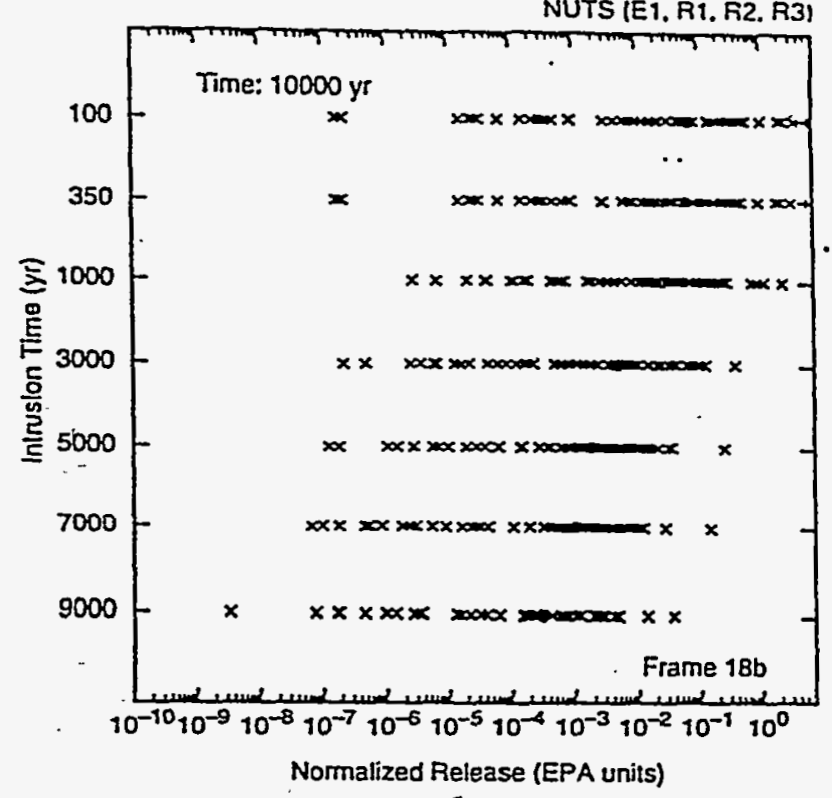

TRI-6342-5728-0

Fig. 18. Cumulative radionuclide transport over 10,000 yr from repository to Culebra Dolomite for El intrusions: (18a) individual radionuclides with an El intrusion at $1000 \mathrm{yr}$, and (18b) total release for El intrusions at $100,350,1000,3000,5000,7000$ and $9000 \mathrm{yr}$.

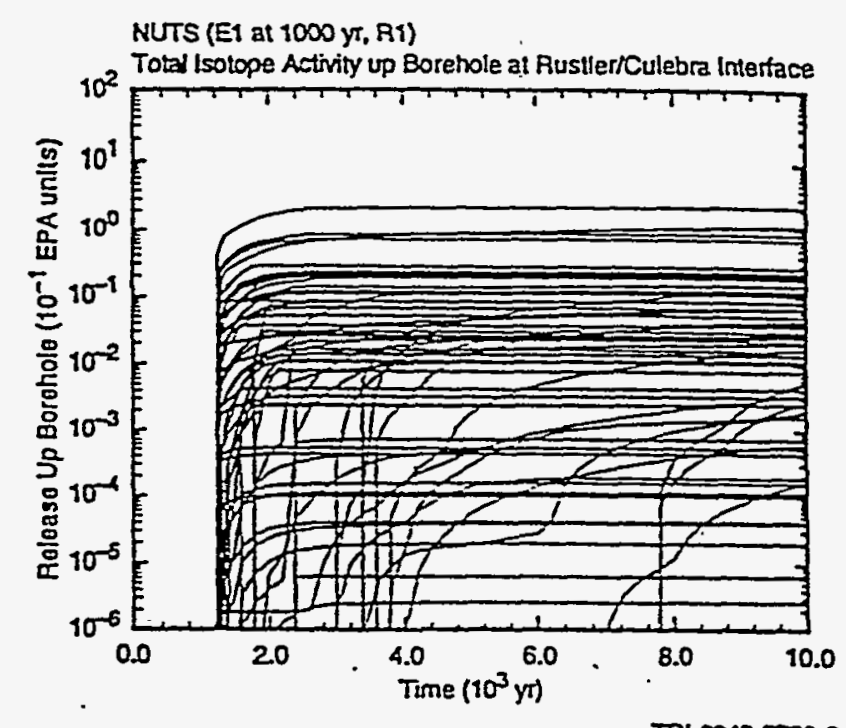

Fig. 19. Cumulative nomalized release from repository to Culebra Dolomite for an El intrusion at $1000 \mathrm{yr}$. 

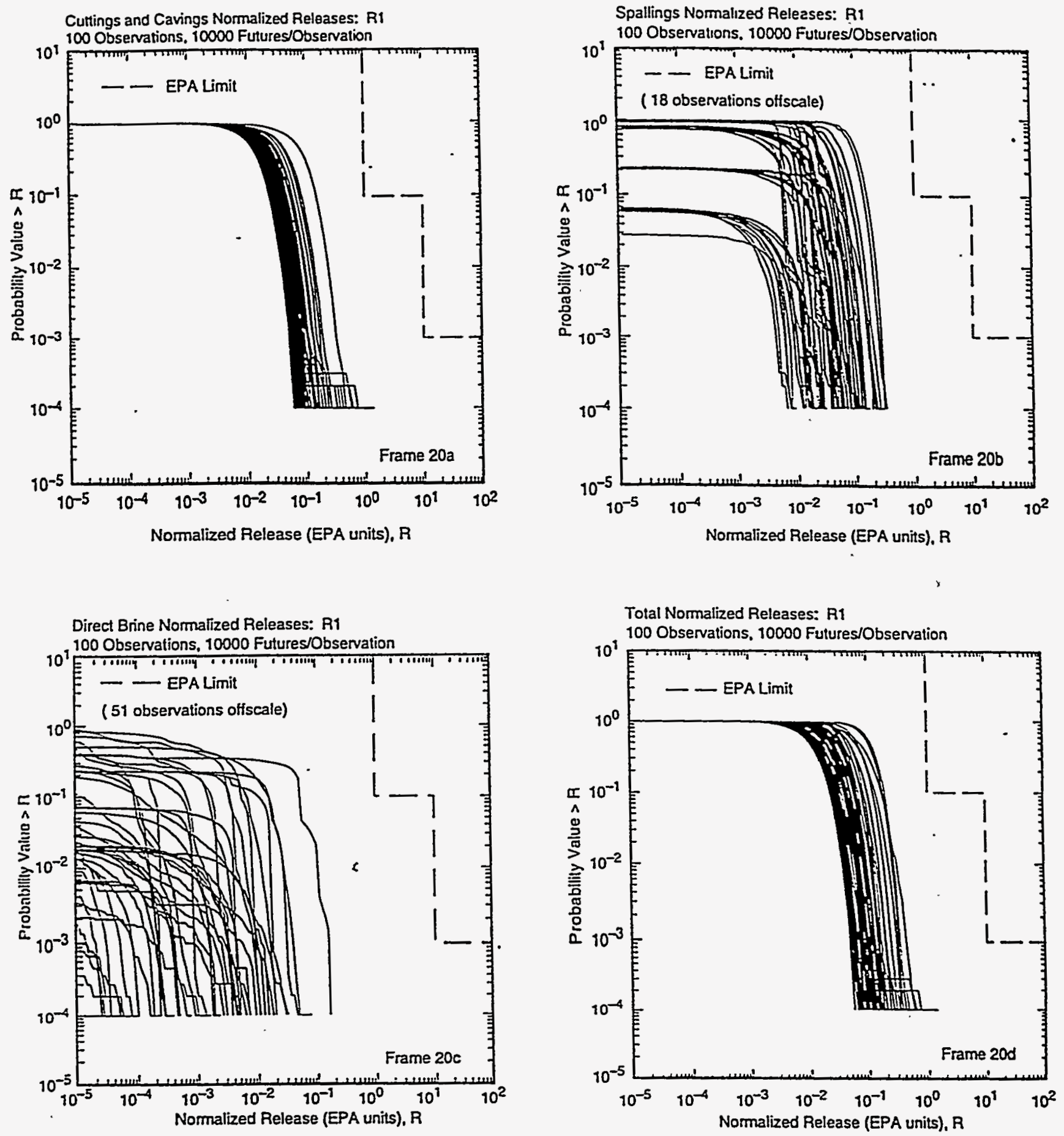

TAl-6342.5727-0

Fig. 20. Distributions of CCDFs for normalized release to the accessible environment over $10,000 \mathrm{yr}$ for replicate RI: (20a) cuttings and cavings, (20b) spallings, (20c) direct brine release, and (20d) total release (Figs. 6. 9, Ref. 38). 


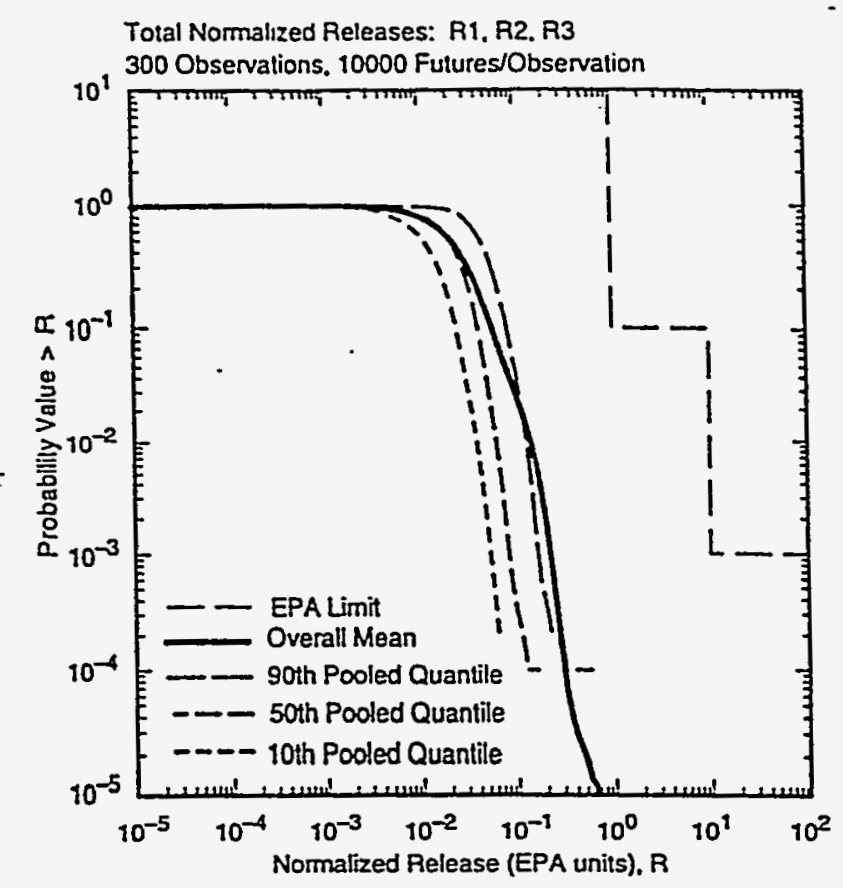

TRI-6342-5726-00

Fig. 21. Mean and percentile curves for total normalized release (i.e., cuttings, cavings, spallings and direct brine) to the accessible environment over 10,000 yr obtained by pooling results for replicates R1, R2 and R3.
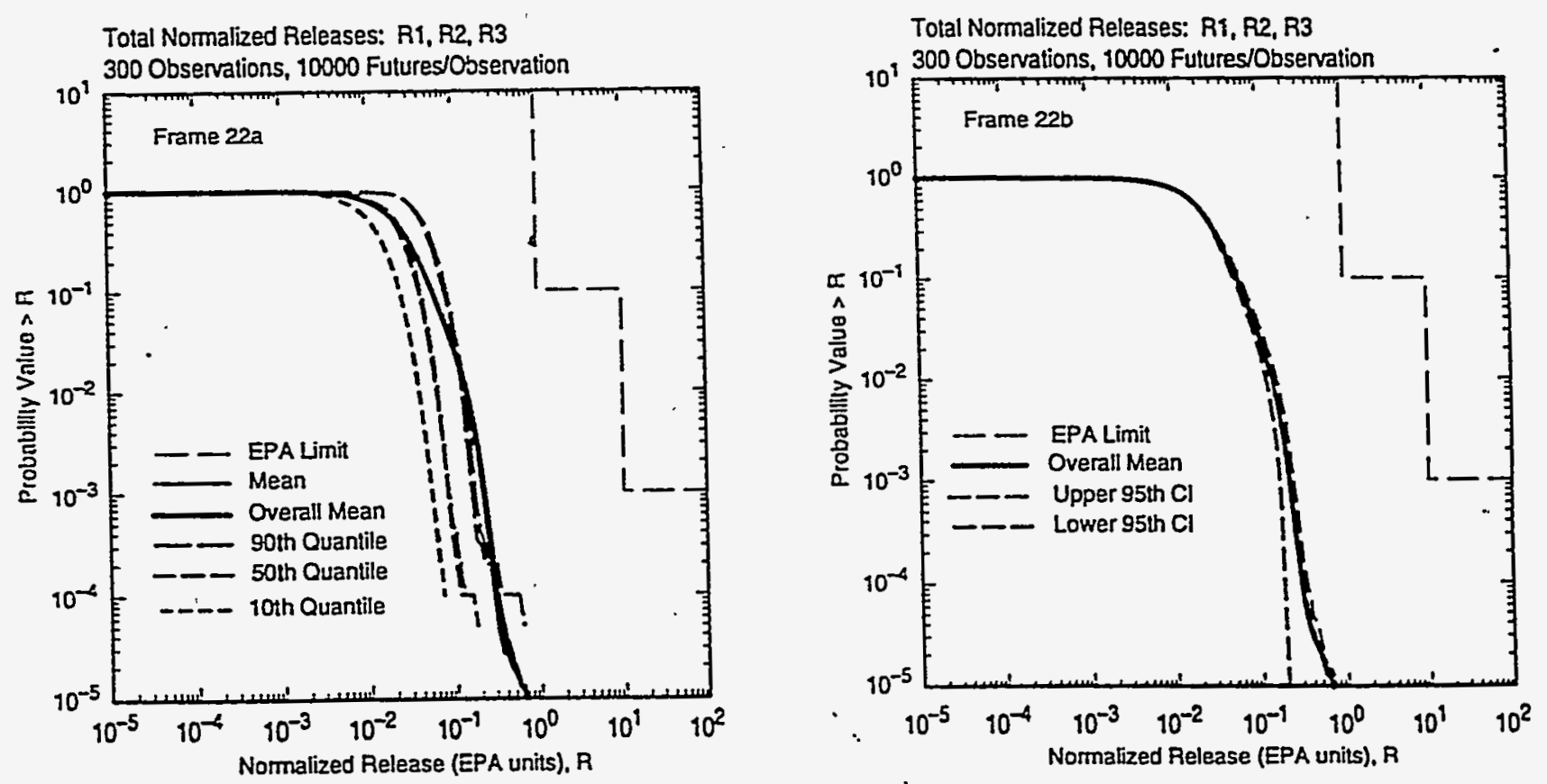

Fig. 22. Outcome of replicated sampling for distribution of CCDFs for total normalized release to the accessible environment over 10,000 yr: (22a) mean and percentile curves for individual replicates, and (22b) confidence intervals (CIs) on mean curve obtained from the three replicates (Fig. 8, Ref. 38). 
Table II. Natural FEPs and Their Screening Classifications (adapted from Table 6-3, Ref. 5)

GEOLOGICAL FEPs (Sect. SCR.1.1. Ref. 5): 1. Stratigraphy. 1.1 Stratigraphy (UP). 1.2 Brine rescrvoirs (DP). 2. Tectonics. 2.1 Changes in regional stress (SO-C). 2.2 Regional tectonics (SO-C). 2.3 Regional uplift and subsidence (SO-C). 3. Structural FEPs. 3.1 Deformation. 3.1.1. Salt deformation (SO-P. UP near rcpository). 3.1.2 Diapirism (SO-P). 3.2 Fracture development. 3.2.1 Formation of fractures (SO-P. UP ncar repository). 3.2.2 Changes in fracture properties (SO-C. UP near repository). 3.3 Fault movement. 3.3.1 Formation of new faults (SO-P). 3.3.2 Fault movement (SO-P). 3.4 Seismic activity. 3.4.1 Seismic activity (UP). 4. Crustal processes. 4.1 Igneous activity. 4.1.1 Volcanic activity (SO-P). 4.1.2 Magmatic activity (SO-C). 4.2 Metamorphism. 4.2.1 Metamorphic activity (SO-P). 5. Geochemical FEPs. 5.1 Dissolution. 5.l.1 Shallow dissolution (UP). 5.1.2 Lateral dissolution (SO-C). 5.1.3 Deep dissolution (SO-P). 5.1.4 Solution chimneys (SO-P). 5.1.5 Breccia pipes (SO-P). 5.1.6 Collapse breccias (SO-P). 5.2 Mineralization. 5.2.1 Fracture infills (SO-C).

SUBSURFACE HYDROLOGICAL FEPs (Sect. SCR.1.2, Ref. 5): 1. Groundwater characteristics. 1.1 Saturated groundwater flow (UP). 1.2 Unsaturated groundwater flow (UP, SO-C in Culebra). 1.3 Fracture flow (UP). 1.4 Density effects on groundwater flow (SO-C). 1.5 Effects of preferential pathways (UP, UP in Salado and Culebra. 2. Changes in groundwater flow. 2.1 Thermal effects on groundwater flow (SO-C). 2.2 Saline intrusion (SO-P). 2.3 Freshwater intrusion (SO-P). 2.4 Hydrological response to earthquakes (SO-C). 2.5 Natural gas intrusion (SO-P).

SUBSURFACE GEOCHEMICAL FEPs (Sect. SCR.1.3, Ref. 5): 1. Groundwater geochemistry. 1.1 Groundwater geochemistry (UP). 2. Changes in groundwater chemistry. 2.1 Saline intrusion (SO-C). 2.2 Freshwater intrusion (SO-C). 2.3 Changes in groundwater Eh (SO-C). 2.4 Changes in groundwater $\mathrm{pH}$ (SO-C). 2.5 Effects of dissolution (SO-C).

GEOMORPHOLOGICAL FEPs (Sect. SCR.1.4, Ref. 5): 1. Physiography. 1.1 Physiography (UP). 2. Meteorite impact. 2.1 Impact of a large meteorite (SO-P). 3. Denudation. 3.1 Weathering. 3.1.1 Mechanical weathering (SO-C). 3.1.2 Chemical weathering. 3.2 Erosion. 3.2.1 Aeolian erosion (SO-C). 3.2.2 Fluvial erosion (SO-C). 3.2.3 Mass wasting (SO-C). 3.3 Sedimentation. 3.3.1 Aeolian deposition (SO-C). 3.3.2 Fluvial deposition (SO-C). 3.3.3 Lacustrine deposition (SO-C). 3.3.4 Mass Wasting (SO-C). 4. Soil development. 4.1 Soil development (SO-C).

SURFACE HYDROLOGICAL FEPS (Sect. SCR.1.5, Ref. 5): 1. Fluvial. 1.1 Stream and river flow (SO-C). 2. Lacustrine. 2.1 Surface water bodies (SO-C). 3. Groundwater recharge and discharge. 3.1 Groundwater discharge (UP). 3.2 Groundwater recharge (UP). 3.3 Infiluration (UP, UP for climate change effects). 4. Changes in surface hydrology. 4.1 Changes in groundwater recharge and discharge (UP). 4.2 Lake formation (SO-C). 4.3 River flooding (SO-C).

CLIMATIC FEPs (Sect. SCR.1.6, Ref. 5): 1. Climate. 1.1 Precipitation (for example, rainfall) (UP). 1.2 Temperature (UP). 2. Climate change. 2.1 Meteorological. 2.1.1 Climate change (UP). 2.2 Glaciation. 2.2.1 Glaciation (SO-P). 2.2.2 Permafrost (SO-P).

MARINE FEPs (Sect. SCR.1.7, Ref. 5): 1. Seas. 1.1 Seas and oceans (SO-C). 1.2 Estuaries (SO-C). 2. Marine sedimentology. 2.1 Coastal erosion (SO-C). 2.2 Marine sediment transport and deposition (SO-C). 3. Sea level changes. 3.1 Sea level changes (SO-C).

ECOLOGICAL FEPs (Sect. SCR.1.8, Ref. 5): 1. Flora and fauna. 1.1 Plants (SO-C). 1.2 Animals (SO-C). 1.3 Microbes (SO-C, UP for colloidal effects and gas generation). 2. Changes in flora and fauna. 2.1 Natural ecological development (SO-C).

Legend: UP - FEPs accounted for in the assessment calculations for undisturbed performance for $40 \mathrm{CFR} \$ 191.13$ (as well as 40 CFR $\$ 191.15$ and Subpart C of 40 CFR Part 191): DP - FEPs accounsed for (in addition to all UP FEPs) in the assessment calculations for disturbed performance for 40 CFR § 191.13: SO-R - FEPs eliminated from performance assessment calculations on the basis of regulations provided in 40 CFR Part 191 and criteria provided in 40 CFR Part 194: SO-C - FEPs eliminated from performance assessment (and compliance assessment) calculations on the basis of consequence: SO-P - FEPs eliminated from performance assessment (and compliance assessment) calculations on the basis of low probability of occurrence. 
Table III. Definitions and Distributions for Individual Elements $t_{i}, l_{i}, e_{j}, b_{i}, p_{i}, a_{i}$ and $t_{\min }$ of Vectors $x_{s t}$ in Sample Space $\mathcal{S}_{s t}$ for Stochastic Uncertainty

$t_{i}$ : Time (yr) of $i^{\text {th }}$ drilling intrusion within area marked by a berm as part of a system of passive institutional controls (Fig. 3, Ref. 38) with $t_{1} \leq t_{2} \leq \ldots \leq t_{n} \leq 10,000$ yr and occurrence of individual drilling intrusions following a Poisson process with a time-dependent rate $\lambda_{d}(t)$ defined by $\lambda_{d}(t)=0 \mathrm{yr}^{-1}$ for $0 \leq t \leq 100 \mathrm{yr}, \lambda_{d}(t)=2.94 \times 10^{-5}$. $\mathrm{yr}^{-1}$ for $100<t \leq 700 \mathrm{yr}$ and $\lambda_{d}(t)=2.94 \times 10^{-3} \mathrm{yr}^{-1}$ for $700<t \leq 10,000 \mathrm{yr}$. Base drilling rate defined to be 46.8 drilling intrusions $/ \mathrm{Lm}^{2} / 10^{4} \mathrm{yr}$ after $700 \mathrm{yr}$ (App. DEL, Ref. 5), with no drilling intrusions possible between 0 and 100 yr due to active institutional controls (Chapt. 7, Ref. 5) and a two order of magnitude reduction in drilling rate between 100 and 700 yr due to passive institutional controls (Ref. 43). Additional information: Sect. 3.2, Ref. 44.

$l_{i}$ : Integer designator for 144 discretized locations for drilling intrusions within area marked by a berm as part of a system of passive institutional controls (Fig. 3, Ref. 38). Probability $p L_{j}$ that drilling intrusion $i$ will occur at location $L_{j}, j=1,2, \ldots, 144$, in Fig. 3 of Ref. 38 is $p L_{j}=1 / 144=6.94 \times 10^{-3}$. Additional information: Sect. 3.3, Ref. 44 .

$e_{i}$ : Integer designator for whether or not drilling intrusion $i$ penetrates an excavated area of the repository (i.e., $e_{i}=$ 0,1 implies penetration of nonexcavated, excavated area, respectively). Corresponding probabilities $p E_{0}, p E_{1}$ for $e_{i}$ $=0,1$ are $p E_{0}=0.791, p E_{1}=0.209$ and derive from excavated and nonexcavated areas within berm (Fig. 3, Ref. 38). Additional information: Sect. 3.4, Ref. 44.

$b_{i}$ : Integer designator for whether or not drilling intrusion $i$ penetrates pressurized brine in the Castile Fm (i.e., $b_{i}=$ 0,1 implies nonpenetration, penetration of pressurized brine; see Sect. 2.2, Vol. 2, Ref. 4, for detailed stratigraphy). Corresponding probabilities for $b_{i}=0,1$ are $p B_{0}=0.08, p B_{1}=0.92$. Additional information: Ref. 45; Sect. 3.5, Ref. 44.

$p_{i}$ : Integer designator for plugging pattern used for drilling intrusion $i$, with (i) $p_{i}=1$ corresponding to a full concrete plug through Salado Fm to Bell Canyon Fm with a permeability of $5 \times 10^{-17} \mathrm{~m}^{2}$, (ii) $p_{i}=2$ corresponding to a two plug configuration with conçete plugs at Rustler/Salado interface and Castile/Bell Canyon interface, and (iii) $p_{i}=3$ corresponding to a three plug configuration with concrete plugs at Rustler/Salado, Salado/Castile and Castile/Bell Canyon interfaces. The probability that a given drilling intrusion will be sealed with plugging pattern $j, j$ $=1,2,3$, is given by $p P L_{j}$, where $p P L_{1}=0.02, p P L_{2}=0.68$ and $p P L_{3}=0.30$. Additional information: Ref. 46 ; App. DEL, Ref. 5; Sect. 3.6, Ref. 44.

$a_{i}$ : Designator for type of waste penetrated by drilling intrusion $i$. The waste intended for disposal at the WIPP is divided in 570 distinct waste streams (see Table 3.7.1, Fig. 3.7.1, Ref. 44), with 569 of these waste streams designated as contact handled (CH)-TRU waste and one waste stream designated as remotely-handled (RH)-TRU waste. Each waste drum emplaced at the WIPP will contain waste from a single $\mathrm{CH}-\mathrm{TRU}$ waste stream. Given that the CH-TRU drums will be stacked three high, each drilling intrusion through CH-TRU waste will intersect three waste streams. In contrast, there is only one waste stream for RH-TRU waste with RH-TRU waste being emplaced separately from CH-TRU waste, and so each drilling intrusion through RH-TRU waste will intersect this single waste stream. Specifically, $\mathrm{a}_{i}=a_{i}=0$ if $e_{i}=0$ (i.e., if the $i^{\text {th }}$ drilling intrusion does not penetrate an excavated area of the 
Table III. Definitions and Distributions for Individual Elements $t_{i} l_{i}, e_{j}, b_{i}, p_{i}, a_{i}$ and $t_{\min }$ of Vectors $x_{s t}$ in Sample Space $S_{s t}$ for Stochastic Uncertainty (Continued)

repository): $a_{i}=a_{i}=1$ if $e_{i}=1$ and RH-TRU waste is penetrated; and $a_{i}=\left[2, i \mathrm{CH}_{i 1}, i \mathrm{CH}_{i 2}, i \mathrm{CH}_{i 3}\right]$ if $c_{i} \ddot{=1}$ and $\mathrm{CH}-$ TRU waste is penetrated, where $\mathrm{iCH}_{i \mathrm{I}}, i \mathrm{CH}_{i 2}$ and $\mathrm{iCH}_{\mathrm{i3}}$ are designators for the $\mathrm{CH}-\mathrm{TRU}$ waste streams intcrsected by the $i^{\text {th }}$ drilling intrusion. Whether the $i^{\text {th }}$ intrusion penetrates a nonexcavated or excavated area is determined by the probabilities $p E_{0}$ and $p E_{1}$ defined in conjunction with $e_{i}$. Given that the $i^{\text {th }}$ intrusion penetrates an excavated area, the probabilities $p C H$ and $p R H$ of penetrating $\mathrm{CH}$ - and RH-TRU wastes are given by 0.876 and 0.124 . respectively (Sect. 3.7, Ref. 44). The probabilities of the individual CH-TRU waste streams are indicated in Table 3.7.1 of Ref. 44. Additional information: Ref. 37; Sect. 3.7, Ref. 44.

$t_{\min }$ : Time (yr) at which mining of potash deposits within land withdrawal boundary occurs. Assumed to follow a Poisson process (p. 5242, Ref. 32) with a time-dependent rate $\lambda_{m}(t)$ defined by $\lambda_{m}(t)=0 \mathrm{yr}^{-1}$ for $0 \leq t \leq 100 \mathrm{yr}$, $\lambda_{m}(t)=1 \times 10^{-6} \mathrm{yr}^{-1}$ for $100<t \leq 700 \mathrm{yr}$, and $\lambda_{m}(t)=1 \times 10^{-4} \mathrm{yr}^{-1}$ for $700<t \leq 10,000 \mathrm{yr}$, with no mining possible between 0 and 100 yr due to active institutional controls (Chapt. 7, Ref. 5) and a two order of magnitude reduction in the mining rate between 100 and 700 yr due to passive institutional control (Ref. 43). Additional information: Sect. 3.8, Ref. 44 . 
BRAGFLO: Calculates multiphase flow of gas and brine through a porous, heterogeneous reservoir. Uses finite difference procedures to solve system of nonlinear partial differential equations that describes the mass conservation of gas and brine along with appropriate constraint equations, initial conditions and boundary conditions. Additional information: Ref. 47; Sect. 4.2, Ref. 44.

BRAGFLO_DBR: Special configuration of BRAGFLO model used in calculation of dissolved radionuclide ${ }^{\circ}$ releases to the surface (i.e., direct brine releases) at the time of a drilling intrusion. Uses initial value conditions obtained from calculations performed with BRAGFLO and CUTIINGS_S. Additional information: Ref. 4S: Sect. 4.7, Ref. 44.

CUTIINGS_S: Calculates the quantity of radioactive material brought to the surface in cuttings and cavings and also in spallings generated by an exploratory borehole that penetrates a waste panel, where cuttings designates material removed by the drillbit, cavings designates material eroded into the borehole due to shear stresses resulting from the circular flow of the drilling fluid (i.e., mud), and spallings designates material carried to the borehole at the time of an intrusion due to the flow of gas from the repository to the borehole. Spallings calculation uses initial value conditions obtained from calculations performed with BRAGFLO. Outside reviewers expressed some concern over the spallings model incorporated into CUTTINGS_S but concluded that this model did not overestimate the size of the spallings release. ${ }^{49}$ Additional information: Refs. 50, 51; Sects. 4.5, 4.6, Ref. 44.

GRASP-INV: Generates transmissivity fields (estimates of transmissivity values) conditioned on measured transmissivity values and calibrated to steady-state and transient pressure data at well locations using an adjoint sensitivity and pilot-point technique. Additional information: Refs. 52, 53.

NUTS: Solves system of partial differential equations for radionuclide transport in vicinity of repository. Uses brine volumes and flows calculated by BRAGFLO as input. Additional information: Ref. 54: Sect. 4.3, Ref. 14 .

PANEL: Calculates rate of discharge and cumulative discharge of radionuclides from a waste panel through an intriding borehole. Discharge is a function of fluid flow rate, elemental solubility and radionuclide inventory: Uses brine volumes and flows calculated by BRAGFLO as input. Based on solution of system of linear ordinary differential equations. Additional information: Ref. 54; Sect. 4.4, Ref. 44.

SANTOS: Solves quasistatic, large deformation, inelastic response of two-dimensional solids with finite element techniques. Used to determine porosity of waste as a function of time and cumulative gas generation, which is an input to calculations performed with BRAGFLO. Additional information: Refs. 47, 55, 56; Sect. 4.2.3, Ref. 44.

SECOFL2D: Calculates single-phase Darcy flow for groundwater flow in two dimensions. The formulation is based on a single partial differential equation for hydraulic head using fully implicit time differencing. Uses transmissivity fields generated by GRASP-INV. Additional information: Refs. 57,58; Sect. 4.8, Ref. 44.

SECOTP2D: Simulates transport of radionuclides in fractured porous media. Solves two partial differential equations: one provides two-dimensional representation for convective and diffusive radionuclide transport in fractures and the other provides one-dimensional representation for diffusion of radionuclides into rock matrix surrounding the fractures. Uses flow fields calculated by SECOFL2D. Additional information: Refs. 57, 58; Sect. 4.9, Ref. 44. 
Table y. Example Elements of $x_{s u}$ in the 1996 WIPP PA (see App. PAR, Ref. 5, and Table 5.2.1, Ref. 44 , for a complete listing of the $n V=57$ elements of $x_{s u}$ and sources of additional information)

ANHPRM - Logarithm of anhydrite permeability $\left(\mathrm{m}^{2}\right)$. Used in BRAGFLO. Distribution: Student's $t$-distribution with 5 degrees of freedom. Range: -21.0 to -17.1 (i.e., permeability range is $1 \times 10^{-21}$ to $1 \times 10^{-17.1} \mathrm{~m}^{2}$ ). Mean, Median: $-18.9,-18.9$. Correlation : -0.99 rank correlation with ANHCOMP (Bulk compressibility of anhydrite, $\mathrm{Pa}^{-1}$ ).

BPCOMP - Logarithm of bulk compressibility of brine pocket $\left(\mathrm{Pa}^{-1}\right)$. Used in BRAGFLO. Distribution: Triangular. Range: -11.3 to -8.00 (i.e., bulk compressibility range is $1 \times 10^{-11.3}$ to $1 \times 10^{-8} \mathrm{~Pa}^{-1}$ ). Mean, mode: -9.80, -10.0. Correlation: -0.75 rank correlation with BPPRM (Logarithm of brine pocket permeability, $\mathrm{m}^{2}$ ).

HALPRM-Logarithm of halite permeability $\left(\mathrm{m}^{2}\right)$. Used in BRAGFLO: Distribution: Uniform. Range: -24 to -21 (i.e., permeability range is $1 \times 10^{-24}$ to $1 \times 10^{-21} \mathrm{~m}^{2}$ ). Mean, median: $-22.5,-22.5$. Correlation: -0.99 rank correlation with HALCOMP (Bulk compressibility of halite, $\mathrm{Pa}^{-1}$ ).

WMICDFLG Pointer variable for microbial degradation of cellulose. Used in BRAGFLO. Distribution: Discrete, with $50 \% 0,25 \% 1,25 \% 2$. WMICDFLG $=0,1,2$ implies no microbial degradation of cellulose, microbial degradation of only cellulose, microbial degradation of cellulose, plastic and rubber.

WTAUFAIL_Shear strength of waste (Pa). Used in CUTTINGS_S. Distribution: Uniform. Range: 0.05 to 10 Pa. Mean, median: $5.03 \mathrm{~Pa}, 5.03 \mathrm{~Pa}$. 
Table VI. Mechanistic Calculations Performed as Part of the 1996 WIPP PA

\section{BRAGFLO}

Individual Calculations ( 6 cases): E0 (i.e., undisturbed conditions); El at 350, 1000 yr (i.e., drilling intrusion through repository that penetrates pressurized brine in the Castile Fm); E2 at 350, 1000 yr (i.e., drilling inirusion through repository that does not penetrate pressurized brine in the Castile Fm); E2E1 with E2 intrusion at 800 yr and El intrusion at 2000 yr. Total calculations: $6 n R n L H S=6 \bullet 3 \bullet 100=1800$.

\section{CUTTINGS_S}

Individual Calculations (52 cases): Intrusion into lower waste panel in previously unintruded (i.e., E0 conditions) repository at 100,350,1000,3000,5000,10,000 yr; Intrusion into upper waste panel in previously unintruded repository at 100,350,1000,3000,5000,10,000 yr; Initial E1 intrusion at $350 \mathrm{yr}$ followed by a second intrusion into the same waste panel at $550,750,2000,4000$ or $10,000 \mathrm{yr}$, Initial El intrusion at $350 \mathrm{yr}$ followed by a second intrusion into a different waste panel at 550,750,2000,4000 or 10,000 yr, Initial Ė intrusion at $1000 \mathrm{yr}$ followed by a second intrusion into the same waste panel at $1200,1400,3000,5000$ or $10,000 \mathrm{yr}$; Initial E1 intrusion at 1000 yr followed by a second intrusion into a different waste panel at $1200,1400,3000,5000$ or $10,000 \mathrm{yr}$; same 23 cases for initial E2 intrusions as for initial E1 intrusions. Total calculations: $52 n R$ nLFS $=52 \cdot 3 \cdot 100=15,600$.

\section{BRAGFLO_DBR}

Same computational cases as for CUTTINGS_S.

\section{NUTS}

Individual Calculations (15 cases): E0; $\mathrm{E} 1$ at 100, 350, 1000, 3000, 5000, 7000, $9000 \mathrm{yr} ; \mathrm{E} 2$ at 100, 350, 1000, $3000,5000,7000,9000$ yr. Screening calculations: $5 n R$ nLHS $=1500$. Total NUTS calculations: 594. Note: Screening calculations were initially performed for each LHS element (i.e., E0, E1 at 350 and 1000 yr, E2 at 350 and $1000 \mathrm{yr}$, which produces the multiplier of 5 in the calculation of the number of screening calculations) to determine if the potential for a radionuclide release existed, with a full NUTS calculation only being performed when such a potential existed.

\section{PANEL}

Individual Calculations ( 7 cases): E2E1 at 100, 350, 1000, 2000, 4000, 6000, 9000 yr. Total calculations: $7 \mathrm{nR}$ $n L H S=7 \cdot 3 \cdot 100=2100$. Note: Additional PANEL calculations were also performed at $100,125,175,350$, $1000,3000,5000,7500$ and 10,000 yf for Salado-dominated brines and also for Castile-dominated brines to determine dissolved radionuclide concentrations for use in the determinations of direct brine releases.

\section{SECOFL2D}

Individual Calculations ( 2 cases): Partially mined conditions in vicinity of repository (i.e., conditions before $r_{\min }$ ); Fully mined conditions in vicinity of repository (i.e., conditions after $t_{\min }$ ). Total calculations: $2 n R n L H S=2 \bullet 3 \bullet$ $100=600$.

\section{SECOTP2D}

Individual Calculations ( 2 cases): Partially mined conditions in vicinity of repository; Fully mined conditions in vicinity of repository. Total calculations: $2 n R n L H S=2 \bullet 3 \bullet 100=600$. Note: Each calculation is for four radionuclides: Am-241, Pu-239, Th-230, U-234. Further, calculations are done for unit releases at time 0 yr, which can then be used to construct transport results for the Culebra for arbitrary time-dependent release rates into the Culebra (Sect. 12.2 Ref. 44). 
Table VII. Results Available for each LHS element $x_{s u . k}$ from Calculations with CUTTINGS_S for Use in CCDF Construction for Spallings Releases

$C_{C H}\left(\tau_{k}\right.$ ): concentration (EPA units $/ \mathrm{m}^{3}$ ) in $\mathrm{CH}$-TRU waste at time $\tau_{k}$, where $\tau_{k}, k=1,2, \ldots, 9$, corresponds to $100,125,175,350,1000,3000,5000,7500$ and 10,000 yr, respectively. See curve "CH-TRU waste within waste panels" in Fig. 10. Source: Refs. 37, 71.

$V S_{E O . v\left(\tau_{k}\right):}$ volume $\left(\mathrm{m}^{3}\right)$ of original (i.e., uncompacted) material released by a drilling intrusion into a previously unintruded repository at time $\tau_{k}$ that encounters CH-TRU waste in an upper waste panel, where $\tau_{k}$. $k=1,2, \ldots, 6$, comesponds to $100,350,1000,3000,5000$ and $10,000 \mathrm{yr}$, respectively. See Fig. 13a. Source: CUTIINGS_S.

$V S_{E 0, L}\left(\tau_{k}\right):$ same as $V S_{E 0 . U}\left(\tau_{k}\right)$ but for intrusion into a lower waste panel.

$V S_{E 1, S}\left(\tau_{j}, \Delta \tau_{i k}\right)$ : volume $\left(\mathrm{m}^{3}\right)$ of original (i.e., uncompacted) material released by second drilling intrusion at time $\tau_{j}+\Delta \tau_{j k}$ into the same waste panel penetrated by an initial El intrusion at time $\tau_{j}$, where (i) $\tau_{j}, j=1,2$, corresponds to 350 and $1000 \mathrm{yr}$; (ii) $\tau_{1}+\Delta \tau_{1 k}, k=1,2, \ldots, 7$, corresponds to $350,550,750,2000,4000$, 10,000 , and $10,250 \mathrm{yr}$ (i.e., $\Delta \tau_{\mathrm{lk}}=0,200,400,1650,3650,9650,9900 \mathrm{yr}$ ), results for $k=2,3, \ldots, 6$ are summarized in Fig. 9.3.6 of Ref. $44, V S_{E 1 . S}\left(\tau_{1}, \Delta \tau_{11}\right)=V S_{E 1 . S}\left(\tau_{1}, \Delta \tau_{12}\right)$ (i.e., $V S_{E 1 . S}(350,0)=V S_{E 1 . S}(350$. $200)$ ), and $V S_{E 1 . S}\left(\tau_{1}, \Delta \tau_{16}\right)=V S_{E 1.5}\left(\tau_{1}, \Delta \tau_{17}\right)$ (i.e., $\left.V S_{E 1 . S}(350,9650)=V S_{E 1 . S}(350,9900)\right)$, and (iii) $\tau_{2}+$ $\Delta \tau_{2 k}, k=1,2, \ldots, 6$, corresponds to $1000,1200,1400,3000,5000$ and $10,000 \mathrm{yr}$ (i.e., $\Delta \tau_{2 k}=0,200,400$, $1000,4000,9000 \mathrm{yr}$ ), results for $k=2,3, \ldots, 6$ are summarized in Fig. 14a, and $V S_{E 1.5}\left(\tau_{2}, \Delta \tau_{21}\right)=$ $V S_{E 1 . S}\left(\tau_{2}, \Delta \tau_{22}\right)$ (i.e., $V S_{E 1 . S}(1000,0)=V S_{E 1 . S}(1000,200)$ ). Source: CUTTINGS_S. The assignments $V S_{E 1 . S}(350,0)=V S_{E 1 . S}(350,200)$ and $V S_{E 1 . S}(1000,0)=V S_{E 1 . S}(1000,200)$ are made to bracket the time period between the occurrence of the first drilling intrusion and the failure of the plug at the Rustler/Salado interface (see Table 4.2.8, Ref. 44); the assignment $V S_{E 1 . S}(350,9650)=V S_{E 1 . S}(350,9900)$ is made to facilitate the use of $V S_{E 1, s}\left(\tau_{1}, \Delta \tau_{1 k}\right)$ for.initial intrusions before $\tau_{1}=350 \mathrm{yr}$.

$V S_{E 1 . D}\left(\tau_{j i} \Delta \tau_{j k}\right)$ : same as $V S_{E 1 . S}\left(\tau_{i}, \Delta \tau_{i k}\right)$ but for intrusion into different waste panel. See Fig. 9.3.6 of Ref. 44 for initial intrusions at $350 \mathrm{yr}$ and Fig. 14a of this presentation for initial intrusions at $1000 \mathrm{yr}$.

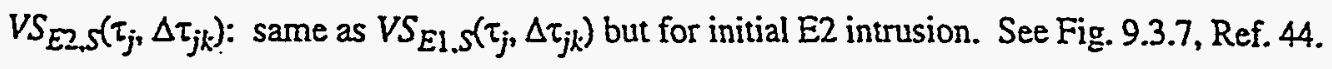

$V S_{E 2 D}\left(\tau_{j}, \Delta \tau_{j k}\right):$ same as $V S_{E 1 . D}\left(\tau_{j}, \Delta \tau_{j k}\right)$ but for initial E2 intrusion. See Fig. 9.3.7, Ref. 44 . 
Table VIII. Determination of Spallings Release $f_{S P}\left[\mathrm{x}_{s t}, f_{B}\left(\mathrm{x}_{s t}\right)\right]$ for an Arbitrary Future $\mathrm{x}_{s t}$

Notation:

$n H_{i}=$ number of intrusions prior to intrusion $i$ that penetrate pressurized brine and use plugging pattern 2 (i.e., two discrete plugs)

$n D=$ number of intrusions required to deplete brine pocket (see BPVOL in Table 5.2.1. Ref. 44. for definition of $n D$ in 1996 WIPP PA)

$\tilde{b}_{i}=0$ if intrusion $i$ into (i) nonexcavated area or (ii) excavated area and plugging pattern 1 used (i.e.. continuous plug)

$=1$ if intrusion $i$ into excavated area, penetrates pressurized brine, plugging pattern 2 used, and $n H_{i} \leq n D$

$=2$ if intrusion $i$ into excavated area and either (i) penetrates pressurized brine, plugging pattern 2 used. and $n H_{i}>n D$, (ii) does not penetrate pressurized brine and plugging pattern 2 used, or (iii) plugging pattern 3 used (i.e., three discrete plugs)

Release $r S P_{i}$ for intrusion into nonexcavated area at time $t_{i}: r S P_{i}=0$.

Release $r S P_{i}$ for intrusion into pressurized repository at time $t_{i}$ (i.e., $i=1$ or $\widetilde{b}_{j}=0$ for $j=1,2, \ldots, i-1$ ):

$$
\begin{aligned}
r S P_{i} & =0 & & \text { if intrusion peneurates RH-TRU waste } \\
& =C_{C H}\left(t_{i}\right)^{2} V S_{E 0 . U}\left(t_{i}\right) & & \text { if } l_{i} \text { in upper waste panel } \\
& =C_{C H}\left(t_{i}\right) V S_{E 0 . L}\left(t_{i}\right) & & \text { if } l_{i} \text { in lower waste panel. }
\end{aligned}
$$

Release $r S P_{i}$ for intrusion into a depressurized repository at time $t_{i}$ with no El intrusion in first $i-1$ intrusions (i.e., $\tilde{b}_{k}=0$ for $k=1,2, \ldots, j-1, \tilde{b}_{j}=2, \bar{b}_{k} \neq 1$ for $\left.k=j+1, j+2, \ldots, i-1\right)$ :

$$
\begin{aligned}
r S P_{i} & =0 & & \text { if intrusion penetrates RH-TRU waste } \\
& =C_{C H}\left(t_{i}\right) V S_{E 2 . .5}\left(t_{j}, t_{i}-t_{j}\right)^{\mathrm{b}} & & \text { if } l_{j}, l_{i} \text { in same waste panel } \\
& =C_{C H}\left(t_{i}\right) V S_{E 2 . D}\left(t_{j}, t_{i}-t_{j}\right), & & \text { if } l_{j}, l_{i} \text { in different waste panels. }
\end{aligned}
$$

Release $r S P_{i}$ for intrusion into a depressurized repository at time $t_{i}$ with first $E 1$ intrusion at time $t_{j}<t_{i}$ (i.e., $\widetilde{b}_{k} \neq 1$ for $k=1,2, \ldots, j-1, b_{j}=1$ ):

$$
\begin{aligned}
r S P_{i} & =0 & & \text { if intrusion penetrates RH-TRU waste } \\
& =C_{C H}\left(t_{i}\right) V S_{E 1.5}\left(t_{j}, t_{i}-t_{j}\right) & & \text { if } l_{j}, l_{i} \text { in same waste panel } \\
& =C_{C H}\left(t_{i}\right) V S_{E 1 . D}\left(t_{j}, t_{i}-t_{j}\right) & & \text { if } l_{j}, l_{i} \text { in different waste panels. }
\end{aligned}
$$

Spallings release $f_{S P}\left[x_{s t}, f_{B}\left(x_{s t}\right)\right]$ :

$$
f_{S P}\left[x_{s i}, f_{B}\left(x_{s t}\right)\right]=\sum_{i=1}^{n} r S P_{i}
$$

\footnotetext{
a Here and elsewhere. appearance of an undefined time implies linear interpolation between defined times in Table VII.

b Here and elsewhere, appearance of two undefined times implies two-dimensional linear interpolation berween defined times in Table VII.
} 